\title{
Article \\ Effect of Production Technique on Pilsner-Style Non-Alcoholic Beer (NAB) Chemistry and Flavor
}

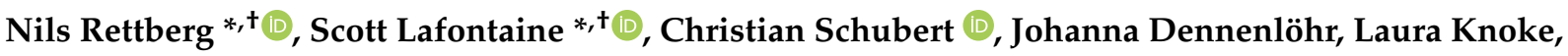 \\ Patrícia Diniz Fischer, Johannes Fuchs and Sarah Thörner
}

Citation: Rettberg, N.; Lafontaine, S.; Schubert, C.; Dennenlöhr, J.; Knoke,

L.; Diniz Fischer, P.; Fuchs, J.; Thörner,

S. Effect of Production Technique on

Pilsner-Style Non-Alcoholic Beer

(NAB) Chemistry and Flavor.

Beverages 2022, 8, 4. https://doi.org/ $10.3390 /$ beverages 8010004

Academic Editor: Koushik Adhikari

Received: 26 November 2021

Accepted: 20 December 2021

Published: 4 January 2022

Publisher's Note: MDPI stays neutral with regard to jurisdictional claims in published maps and institutional affiliations.

Copyright: (c) 2022 by the authors. Licensee MDPI, Basel, Switzerland. This article is an open access article distributed under the terms and conditions of the Creative Commons Attribution (CC BY) license (https:// creativecommons.org/licenses/by/ $4.0 /)$.
Research Institute for Beer and Beverage Analysis, Versuchs-und Lehranstalt für Brauerei in Berlin (VLB) e.V., Seestr. 13, 13353 Berlin, Germany; c.schubert@vlb-berlin.org (C.S.); j.dennenloehr@vlb-berlin.org (J.D.);

1.knoke@vlb-berlin.org (L.K.); diniz.fischer@vlb-berlin.org (P.D.F.); j.fuchs@vlb-berlin.org (J.F.);

s.thoerner@vlb-berlin.org (S.T.)

* Correspondence: n.rettberg@vlb-berlin.org (N.R.); scott.r.lafontaine@gmail.com (S.L.);

Tel.: +49-30-45080106 (N.R.); +49-176-63636721 (S.L.)

+ These authors contributed to this work equally.

\begin{abstract}
The sensory, volatile, and physiochemical profiles of nineteen commercial non-alcoholic pilsner-style beers produced by different production techniques were analyzed and compared with a dry-hopped non-alcoholic IPA. NABs made only with either physical dealcoholization or restricted fermentations differed significantly in chemistry and flavor. Generally, NABs produced by restricted fermentations were the most worty, thick, and sweet, whereas NABs that were physically dealcoholized had the lowest taste/aroma intensities and were the sourest, most thin, and least sweet. Interestingly, the method of dealcoholization had a minor impact on the flavor profile. The use of maltose intolerant yeast as well as the implementation of combined treatments, such as blending dealcoholized beer with beer containing alcohol, were the techniques found to produce NABs with more harmonious and multifaceted chemical and flavor profiles. NABs with increased hop aroma volatiles were the most harmonious, particularly highlighted by the NA IPA reference. Even though dry-hopped character might be atypical for pilsner-style beer, dry-hopping appears as a simple application to produce NABs with more harmonious flavor.
\end{abstract}

Keywords: non-alcoholic beer (NAB); hop aroma; worty; flavor; restricted fermentation; physical dealcoholization

\section{Introduction}

Due to more consumer demand for healthy beverages, increased non-alcoholic beer (NAB) production has recently become an important economic consideration for breweries of nearly all sizes [1]. However, German brewers have been introducing and producing non-alcoholic counterparts to their flagship pilsner beers for decades. Historically, the main NAB styles produced (i.e., based on overall volume sold) have been pilsner and wheat styles followed by beer mixed beverages, such as non-alcoholic Radlers [2]. More recently, small and medium-sized craft breweries have also started to enter the NAB market which has resulted in more product diversity and specifically the increased production of non-alcoholic styles with hoppy flavor profiles, such as India pale ales (IPAs) [3].

The definition of NAB differs from country to country. In many European countries, products are labeled as "non-alcoholic beer" when they contain less than $0.5 \%$ alcohol by volume (ABV). In countries where $\mathrm{NAB}$ is defined by $<0.5 \% \mathrm{ABV}$, the portfolio of many brewers may also include additional $0.0 \% \mathrm{ABV}$ products. These beers are then specifically marketed as " 0.0 " $\mathrm{NAB}$ for religious and/or health reasons.

In the industry, there exist countless approaches to produce NAB but generally these techniques can be split into two main categories: 1 . brewing methods that rely on restricting ethanol formation (biological methods) and 2. those that rely on ethanol removal from 
fully fermented beer (physical methods) [4-7]. Within these two approaches, there exist several different techniques varying in performance, efficiency, and usability. In addition, it is important to point out that for decades the production of commercial non-alcoholic beer has been complex and that brewers have been employing a combination of methods to produce NABs with multifaceted and desirable profiles $[8,9]$.

From a commercial standpoint, one of the main advantages of biological techniques is that they can be usually implemented with equipment that already exists in a brewery. One of the most popular biological techniques used to produce NABs has been restricted fermentation (RF). Common approaches to restricted NAB fermentations are to produce unfermentable/slightly fermentable wort, to limit the contact time between wort and conventional brewing yeast, and/or to apply low fermentation temperatures [10]. Recently, the use of maltose intolerant (MI) Saccharomyces and/or non-Saccharomyces yeasts has also become an increasingly popular biological technique because there is evidence that some of these strains can produce NAB with more fruity flavor profiles [1]. The reviews by Bellut and Arendt [1] and Montanari, Marconi, Mayer, and Fantozzi [10] are great resources to find more specific details on how biological techniques can be applied to produce NAB.

In comparison, methods relying on ethanol removal require significant capital investment for new infrastructure in the brewery. Generally, the techniques used to physically dealcoholize can be divided into thermal and mechanical methods [11,12]. Thermal dealcoholization removes ethanol based on its boiling point, while membrane-based processes rely on pressure or concentration differences to selectively remove ethanol with functionalized semipermeable membranes (i.e., pore size, polarity, charge, etc.). Again, comprehensive reviews by Mangindaan, Khoiruddin, and Wenten [11] and/or Müller, Bellut, Tippmann, and Becker [12] provide much more specific details on the physical methods used for the dealcoholization of beer.

Limited research investigating the main factors influencing the chemical and sensory profiles of NAB exists [13-18]. Lafontaine, Senn, Dennenlöhr, Schubert, Knoke, Maxminer, Cantu, Rettberg, and Heymann [15] recently performed one of the broadest surveys on $\mathrm{NAB}$ and found that even though pilsner NAB styles make up a majority of NAB offerings, the chemical and flavor profiles of commercial NAB being distributed globally are extremely diverse. The same study found that Northern California consumers preferred sweeter NAB with citrusy, tropical, stone fruit aromas associated with increases in terpene alcohols and esters which they assumed were extracted from dry-hopping. Interestingly, an associated study [16] found that NAB with certain flavor profiles related to the inclusion of particular chemical constituents was related to how "beer-like" consumers perceived NAB to be. Unfortunately, the authors were only able to speculate on which techniques might be driving particular flavors because the production methods for most of the NAB evaluated in these studies were largely unknown. Yet, these results are supported by both Forster and Gahr [19] who observed that late hopping positively affected the sensory quality of low alcoholic pilsner type beer, along with Brendel, Hofmann, and Granvogl [14] who more recently postulated that dry-hopping could help increase the consumer popularity of alcohol-free beer because it can modify and mask aromas resulting from thermal dealcoholization and restricted fermentations. Based on all these previous studies there is general agreement that quality defects in pilsner-style NAB result from the lack of fermentation derived aroma compounds as well as the occurrence of a "worty" aroma. Recently, Piornos, Balagiannis, Methven, Koussissi, Brouwer, and Parker [17] found that the worty character in a NAB produced through a restricted fermentation was related to 27 odor active compounds with methional, 3-methylbutanal, (E)- $\beta$-damascenone, 5 -ethyl3-hydroxy-4-methyl2 $(5 \mathrm{H})$-furanone, and phenylacetaldehyde being the most important to consider.

Therefore, it is clear that the influence of different NAB production techniques on NAB flavor has been discussed before. However, studies that have directly compared the comprehensive chemical and sensory analysis of similar NABs but resulting from different production techniques used in the industry are still rare. One reason for this is that the NAB 
production process applied by brewers to make specific commercial products is typically highly confidential. Similarly, although larger brewers have been analyzing competitor products for decades and thereby have ascertained a remarkable amount of knowledge on $\mathrm{NAB}$, most of this data remains unpublished. Additionally, many of the previous studies mentioned were not able to fully deconstruct the volatile and nonvolatile profiles of the NAB they evaluated because they lacked access to the broad range of analytical assays required for this and thus mostly focused on sensory analysis and/or a few chemical classes.

Only two studies have directly assessed the broad impact of production techniques on NAB quality. Schmelzle, Lindemann. and Methner [13] found that the flavor profiles of German NABs were dependent on production methodology and that physical dealcoholization resulted in NAB that was more sour and bitter (although the methodology such as vacuum distillation/membrane was not specified), while NAB produced through restricted fermentation and/or combination of methods was sweeter. In addition, consumers in this study preferred sweet NAB with light fruity aroma and did not prefer NAB that was sour and bitter with malty aroma. However, one disadvantage of this study was that the chemical analysis was limited and the volatile drivers for consumer preference remained speculative.

Comparatively, Ramsey, Yang, Fisk, and Ford [18] recently explored a range of different NAB lagers and unlike the results in Schmelzle, Lindemann, and Methner [13], the authors proposed that pre-processing factors (i.e., raw materials used) and/or post-brewing processes (i.e., the use of additive flavor compounds or dry-hopping) have more of an impact on NAB flavor than the choice of production method. This study also reported that NAB with high bitterness and astringency was least liked by consumers, while NAB that was produced using a combination of methods was the most preferred by consumers. This suggests that the utilization of multiple production techniques in combination might lead to NAB with more balanced flavor profiles. However, they also observed segmentation in their consumer liking data, in that there were "hoppy likers" and "hoppy dislikers", which led them to hypothesize that a wide range of flavor profiles might be needed to satisfy different groups of consumers.

Thus, the results by Schmelzle, Lindemann, and Methner [13] and Ramsey, Yang, Fisk, and Ford [18] differ in the identification of the most important production decisions influencing NAB chemistry and flavor. Additionally, there are limited studies which report a broad breakdown of the volatile and nonvolatile chemistry of NAB. Therefore, the main goals of this study were to (1) deconstruct the chemical and sensory profiles of a selection of pilsner type NABs $(n=19)$ and one non-alcoholic Indian Pale Ale (IPA) produced via a number of different techniques and to (2) determine if certain production techniques yield unique flavor profiles driven by specific chemical constituents. The comparison of a single NAB style produced through a number of production techniques as well as the inclusion of a hop forward reference provides a unique assessment of how impactful different production decisions are to the overall resulting flavor profile of NAB.

\section{Materials and Methods}

\subsection{Collection of Beer Samples}

Throughout this manuscript, the abbreviation NAB is used for beers $<0.5 \% \mathrm{ABV}$, and

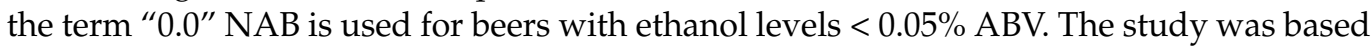
on an analysis of 20 NABs from 18 breweries (Table 1). Out of these 20 NABs, 18 were packaged in either $0.33 \mathrm{~L}$ or $0.5 \mathrm{~L}$ glass bottles ( 14 in brown glass bottles, 4 in green glass bottles) and these samples were purchased from local retailers. Two samples (RF1 and RF3) were packaged in PET bottles and these were purchased from two separate stores. Nineteen out of the $20 \mathrm{NAB}$ were either marketed as "non-alcoholic Pilsner beer", "non-alcoholic lager beer", or their labels contained references such as "bitter" or "extra bitter", which are considered key attributes of Pilsner beer in Germany. Throughout purchasing it was ensured that the products had at least six more months before their "best before date", with the exception of RF1 and RF3 in PET. RF1 and RF3 had 5-month shelf lives and were 
tested approximately 4 weeks after packaging. The beer selection included four labeled as " $0.0 \%$ " NAB, these were $\mathrm{C} 1, \mathrm{C} 2, \mathrm{M} 1$, and V2. The respective production technique of each $\mathrm{NAB}$ was requested by personal communication with the breweries. Nineteen out of the 20 NAB were brewed and bottled in Germany, which means these products were subject to the German beer purity law because they contained "beer" in their label. Therefore, these NABs could only be made with water, barley malt, and hop pellets/extracts [20]. Given this, it was assumed that the differences in the sensory and chemical properties of the NABs would primarily be a function of the processing technique.

Table 1. Summary of basic chemical parameters of NAB grouped according to their production technique and sorted within production technique by ABV.

\begin{tabular}{|c|c|c|c|c|c|c|c|c|c|c|c|}
\hline Sample & Brewery & $\begin{array}{l}\text { Processing } \\
\text { Category }\end{array}$ & $\begin{array}{l}\text { Package } \\
\text { Type }\end{array}$ & $\begin{array}{l}\text { Processing } \\
\text { Notes }\end{array}$ & $\underset{\text { (\%vol.) }}{\text { ABV }}$ & $\begin{array}{c}\text { Real } \\
\text { Extract } \\
\text { (Re) } \\
(\mathrm{g} / \mathbf{1 0 0} \mathrm{g})\end{array}$ & $\begin{array}{l}\text { Calories } \\
(\mathrm{kJ} / 100 \mathrm{~mL})\end{array}$ & $\begin{array}{l}\text { Color } \\
\text { (EBC) }\end{array}$ & $\mathrm{pH}$ & $\begin{array}{l}\mathrm{CO}_{2} \\
(\mathrm{~g} / \mathrm{L})\end{array}$ & IBU \\
\hline $\mathrm{C} 1$ & 3 & Combined & Green bottle & $\begin{array}{c}\text { Natural aroma } \\
\text { added, } 0.0 \% \\
\text { ABV }\end{array}$ & 0.01 & 5.2 & 76 & 7.8 & 4.4 & 4.7 & 13 \\
\hline $\mathrm{C} 2$ & 2 & Combined & Brown bottle & $0.0 \% \mathrm{ABV}$ & 0.01 & 7.8 & 122 & 8.3 & 4.4 & 5.3 & 20 \\
\hline $\mathrm{C} 7$ & 4 & Combined & Brown bottle & & 0.08 & 6.1 & 114 & 8.8 & 4.5 & 4.8 & 20 \\
\hline $\mathrm{C} 3$ & 5 & Combined & Green bottle & & 0.16 & 6.0 & 98 & 8.7 & 4.4 & 5.2 & 21 \\
\hline C5 & 1 & Combined & $\begin{array}{l}\text { Brown bottle } \\
\text { Brown bottle }\end{array}$ & $\begin{array}{l}\text { Unique } \\
\text { hopping }\end{array}$ & 0.36 & 5.3 & 92 & 7.3 & 4.5 & 5.2 & 32 \\
\hline C6 & 2 & Combined & Brown bottle & & 0.40 & 7.0 & 124 & 7.8 & 4.5 & 5.2 & 20 \\
\hline $\mathrm{C} 4$ & 1 & Combined & Brown bottle & $\begin{array}{l}\text { Unique } \\
\text { hopping }\end{array}$ & 0.41 & 6.3 & 106 & 8.4 & 4.4 & 5.2 & 29 \\
\hline C9 & 6 & Combined & Brown bottle & & 0.41 & 8.0 & 133 & 13.0 & 4.3 & 5.7 & 22 \\
\hline $\mathrm{C} 8$ & 7 & Combined & Brown bottle & & 0.43 & 6.1 & 105 & 8.2 & 4.5 & 5.3 & 19 \\
\hline$\overline{\mathrm{M}} 1-$ & $\begin{array}{l}-\overline{8}-- \\
--\frac{-}{-}-\end{array}$ & Membrāāe & Brown bottle & $-\overline{0} \overline{0} \% \mathrm{~A} \overline{\mathrm{B}} \overline{\mathrm{V}}$ & $\underline{0.04}$ & 3.8 & $5 \overline{4}$ & 6.6 & $\overline{4} .0$ & $5 . \overline{3}$ & 11 \\
\hline MI1 & $\overline{9}-$ & $\begin{array}{l}{ }^{-} \overline{\text { Maltose }}{ }^{-} \\
\text {intolerant }\end{array}$ & Brown bottle & & 0.37 & 6.1 & 105 & 7.9 & 4.3 & $5 . \overline{2}$ & 23 \\
\hline MI2 & 10 & $\begin{array}{c}\text { Maltose } \\
\text { intolerant }\end{array}$ & Brown bottle & $\begin{array}{l}\text { Dry-hopped/ } \\
\text { Reference IPA }\end{array}$ & 0.42 & 7.9 & 126 & 18.0 & 4.5 & 5.0 & 38 \\
\hline $\begin{array}{c}----- \\
\text { RF4 }\end{array}$ & ---- & $\begin{array}{c}\overline{\text { Restricted }} \\
\text { fermentation }\end{array}$ & $\begin{array}{c}----- \\
\text { Brown bottle }\end{array}$ & & 0.10 & 6.4 & 104 & 7.5 & & 4.6 & 18 \\
\hline RF2 & 12 & $\begin{array}{l}\text { Restricted } \\
\text { fermentation }\end{array}$ & Green bottle & & 0.11 & 7.2 & 114 & 9.7 & 4.6 & 4.9 & 28 \\
\hline RF1 & 13 & $\begin{array}{l}\text { Restricted } \\
\text { fermentation }\end{array}$ & PET & & 0.19 & 5.6 & 94 & 7.6 & 4.6 & 4.8 & 30 \\
\hline RF3 & 14 & $\begin{array}{l}\text { Restricted } \\
\text { fermentation }\end{array}$ & PET & & 0.25 & 6.9 & 117 & 7.3 & 4.6 & 4.9 & 19 \\
\hline $\mathrm{V} 2$ & 15 & $\begin{array}{l}\text { Vacuum } \overline{-} \\
\text { Distillation }\end{array}$ & Brown bottle & $0.0 \% \mathrm{ABV}$ & 0.01 & 8.9 & 141 & 8.3 & 4.7 & 5.1 & 21 \\
\hline V1 & 16 & $\begin{array}{l}\text { Vacuum } \\
\text { Distillation }\end{array}$ & Brown bottle & & 0.29 & 3.9 & 60 & 6.8 & 4.3 & 5.4 & 33 \\
\hline V3 & 17 & $\begin{array}{l}\text { Vacuum } \\
\text { Distillation }\end{array}$ & Green bottle & & 0.29 & 3.7 & 58 & 7.2 & 4.3 & 4.9 & 30 \\
\hline \multirow[t]{2}{*}{$\mathrm{V} 4$} & \multirow[t]{2}{*}{18} & \multirow[t]{2}{*}{$\begin{array}{l}\text { Vacuum } \\
\text { Distillation }\end{array}$} & \multirow[t]{2}{*}{ Brown bottle } & & 0.34 & 5.3 & 84 & 9.8 & 4.5 & 5.0 & 33 \\
\hline & & & & ${ }^{\%} \mathrm{RSD}$ & $<0.5$ & $<0.5$ & $<0.5$ & $<0.5$ & $<0.5$ & $<0.5$ & $<0.5$ \\
\hline
\end{tabular}

For better visualization, each of the values for each analytical measurement have been colored from low to high in each column. Concentrations are the calculated means of duplicate measurements and not rounded. $\%$ Measurement precision based on relative standard deviation (RSD or \%RSD) from 6-fold repeat analysis of sample C8. ABV-Alcohol by volume. IBU-International bitterness units.

However, based on the results of previous studies, the specific inclusion of two NABs in this study is notable. Due to the previously reported $[14,15,19]$ positive influence of hop aroma on NAB flavor, a non-alcoholic IPA (MI2) was included as a hop-forward reference to further investigate the influence of hops on NAB flavor and chemistry. Similarly, C1 was a NAB imported from the Netherlands and did not fall into the manufacturing practices of the German Purity law. C1 contained a "natural aroma". While adding an aromatic extract is not allowed by German brewing practice, similar to the addition of hops, it has been suggested that this approach can also be an effective approach to produce NAB with multifaceted flavor [21].

The NABs selected for this study fell into five major categories with the following abbreviations being used throughout the paper: use of maltose-intolerant yeast (MI), 
restricted fermentation (RF), membrane dealcoholization (M), vacuum dealcoholization $(\mathrm{V})$, combined/blended treatments (C).

\subsection{NAB Physicochemical Characterization by Industry Standard Methods}

Basic beer characterization was carried out using the following industry standard methods: ethanol (EBC 9.3.1), real extract (EBC 9.4), $\mathrm{pH}$ (EBC 9.35), carbon dioxide (EBC 9.28.3), color (EBC 9.6), bitter units (EBC 9.8), glycerol (EBC 9.33), foam (EBC 9.42.2), and protein (EBC 9.9.1) [22]. Fermentable carbohydrates were analyzed by HPLC with refractive index detection according to EBC 9.27 [22]. This method results in the separation and quantification of fructose, glucose, sucrose, maltose, and maltotriose. Dextrins were determined using the method and calculation as described by the Mitteleuropäische Brautechnische Analysenkommission (MEBAK) in Chapter 2.10.3.2 and 2.10.3.4 [23]. As recommended by EBC and MEBAK, samples were analyzed in duplicates and the mean values are reported herein. To assist the reader in identifying whether the analysis results for the different NABs are significantly different for a given analyte, the measurement precision for each analyte is reported (see Tables 1 and S1). Throughout the manuscript, measurement precision is defined and reported as the relative standard deviation (\%RSD) calculated from a 6 -fold repeat analysis. This was done by either measuring sample C8, standard domestic lager beers, or a reference solution. For parameters in which the standard lager beers or reference solution were used, the mean value of the 6-fold repeat analysis is reported and falls in the range of the NABs investigated (Tables 1 and S1) in this study.

\subsection{Volatile Beer Analyses}

For the analysis of volatiles, either industry standard methods, published peerreviewed methods, or modified published methods were applied. The chemicals and instruments for the industry standard methods as well as the published methods were the same as previously reported in the associated citation, while for the modified methods utilized, more detailed information is provided below. For all of the analyses, duplicate measurements were performed and the mean values are reported herein. As mentioned above, the measurement precision is reported as the relative standard deviation (\%RSD) calculated by performing a 6-fold repeat analysis (Tables S2-S4).

Dimethyl sulfide (DMS) was measured using HS-GC with a pulsed flame photometric detector (PFPD) operated under conditions outlined in MEBAK 2.23.1.1 [23]. Hop-derived aroma compounds were analyzed by headspace solid-phase microextraction (HS-SPME) GC-MS/MS according to the method described previously by Dennenlöhr, et al. [24]. Aldehydes were analyzed by HS-SPME and on-fiber derivatization (OFD) GC-MS/MS as published by Dennenlöhr et al. [25].

The concentrations of acetaldehyde, higher alcohols, and acetate esters were determined by static headspace gas chromatography with flame ionization detection (HS-GC-FID) according to the method EBC 9.39 [22]. The GC-FID instrument used was a Shimadzu GC-2010 (Shimadzu Corp., Kyōto, Japan) equipped with a DB-Wax (60 $\mathrm{m} \times 0.32 \mathrm{~mm} \times 0.5 \mu \mathrm{m}$ film thickness) from Agilent (Santa Clara, CA, USA). Quantification of higher alcohols and esters was reached using butan-1-ol and phenol as internal standards added at a concentration of $15 \mathrm{mg} / \mathrm{L}$. Phenol was used to quantify phenyl ethanol and phenylethyl acetate, while the other volatiles were quantified using butan-1-ol. The calibration ranges of the compounds differed and were as follows: acetaldehyde $(1-75 \mathrm{mg} / \mathrm{L})$, ethyl acetate $(0.5-75 \mathrm{mg} / \mathrm{L})$, propanol $(0.5-75 \mathrm{mg} / \mathrm{L})$, isobutanol (1-75 mg/L), isoamyl acetate $(0.5-10 \mathrm{mg} / \mathrm{L})$, 2-methyl1-butanol (1-75 mg/L), 3-methyl-1-butanol (1-100 mg/L), phenyl ethanol (1-75 mg/L), and phenylethyl acetate $(0.1-5 \mathrm{mg} / \mathrm{L})$ The lowest concentration of the calibration range was defined as limit of quantification for each compound.

Ethyl esters (i.e., ethyl butyrate, ethyl hexanoate, ethyl octanoate, ethyl decanoate, and ethyl dodecanoate) were determined by headspace-solid phase microextraction (HSSPME) gas chromatography-mass spectrometry (GC-MS). The GC-MS system used was a Shimadzu GC-2010 interfaced with a MS-QP2010 Plus (Shimadzu Corp., Kyōto, Japan) 
equipped with a Gerstel MPS 2XL auto sampler (Gerstel, Mühlheim an der Ruhr, Germany) for automated HS-SPME sampling. Esters were extracted from $2 \mathrm{~mL}$ liquid sample using a 50/30 $\mu \mathrm{m} \mathrm{DVB/CAR/PDMS} \mathrm{fiber} \mathrm{(Supelco,} \mathrm{St.} \mathrm{Louis,} \mathrm{MO,} \mathrm{USA),} \mathrm{the} \mathrm{column} \mathrm{used} \mathrm{for}$ chromatographic separation was an HP-5MS UI column $(30 \mathrm{~m} \times 0.25 \mathrm{~mm}$ i.d. $\times 0.25 \mu \mathrm{m}$ film thickness from Agilent (Santa Clara, CA, USA)). The extraction and GC parameters used are described by Dennenlöhr, Thörner, Manowski, and Rettberg [24]. Briefly, the mass spectrometer was operated in selected ion monitoring (SIM) mode, using the following qualifier and quantifier ions: ethyl butyrate $(\mathrm{m} / \mathrm{z} 71$ and $\mathrm{m} / \mathrm{z} 60)$, ethyl hexanoate $(\mathrm{m} / \mathrm{z}$ 88 and $\mathrm{m} / \mathrm{z}$ 101), ethyl octanoate $(\mathrm{m} / \mathrm{z} 88$ and $\mathrm{m} / \mathrm{z} 127)$, ethyl decanoate $(\mathrm{m} / \mathrm{z} 88$ and $\mathrm{m} / \mathrm{z} 73)$, and ethyl dodecanoate $(\mathrm{m} / \mathrm{z} 88$ and $\mathrm{m} / \mathrm{z}$ 101). The calibration range for all ethyl esters ranged from $5 \mu \mathrm{g} / \mathrm{L}$ to $1000 \mu \mathrm{g} / \mathrm{L}$. The lowest concentration of the calibration range $(5 \mu \mathrm{g} / \mathrm{L})$ was defined as the limit of quantification. Isotopically labeled d5-ethyl hexanoate $(\mathrm{m} / \mathrm{z} 93$ and $\mathrm{m} / \mathrm{z} 106)$, was used as an internal standard at a concentration of $100 \mu \mathrm{g} / \mathrm{L}$. Data evaluation was done using the GC-MS solution software Version 4.45 SP1 (Shimadzu Corp., Kyōto, Japan).

The analysis of 3-methyl-2-buten-1-thiol (3-MBT) was performed using the on fiberderivatization (OFD) assay previously published [26], using stable isotope-labeled 3-MBT (d6-3 MBT, aromaLAB, Planegg, Germany) as an internal standard. The conditions used during sample preparation and GC separation were again performed as published [26]. However, the mass spectrometer was operated in electron impact ionization $(70 \mathrm{eV})$ multiple reaction ion monitoring (MRM) mode using the following transitions for quantification and qualification: 3-MBT (m/z 282 $\rightarrow 68$ and $\mathrm{m} / \mathrm{z} 101 \rightarrow 59)$ and d6-3-MBT $(\mathrm{m} / \mathrm{z} 288 \rightarrow 75$ and $\mathrm{m} / \mathrm{z} 107 \rightarrow 62$ ). Calibration across a range from 1 to $100 \mathrm{ng} / \mathrm{L}$ was done using a domestic pilsner-style beer packaged in a $0.5 \mathrm{~L}$ can. For calibration and analysis, d6-3 MBT was added to the samples at a concentration of $100 \mathrm{ng} / \mathrm{L}$ at the very beginning of the sample preparation. GC-MS/MS data evaluation was done using Agilent MassHunter WorkStation-Qualitative Analysis software in Version B.07.00.

\subsection{Sensory Analysis}

To complement the chemical analysis, sensory analysis was performed using modified quantitative descriptive analysis [27]. The NABs were tested throughout five sessions (4 NABs per session) which took place in five consecutive days. The panel consisted of 12 voluntary tasters ( 10 males, 2 females, ranging from 23 to 45 years old). All of the panelists had performed sensory analysis on beer and/or NAB on a regular basis previously and were selected/trained as described in EBC 13.4 [22]. All of the panelists were regularly trained on beer/NAB flavor which included but was not limited to the detection of off-flavors (i.e., worty, diacetyl, etc.) in manipulated/spiked samples, the detection of beer/NAB style-specific characteristics (Figure S1), etc.

The tasting area, equipment, and glassware were also performed following EBC 13.2 [22]. During the sensory sessions, $50 \mathrm{~mL}$ of the samples were served at $8{ }^{\circ} \mathrm{C}$ in brown cylindrical glasses which were coded random three-digit code. Within each session each NAB was tasted once in a completely randomized order, meaning no replicates were performed. The sensory data was collected using a paper ballot and 9-point scales as defined on the ballot (Figure S1). The panelists were asked to first assess the orthonasal aroma of the samples, then to taste the samples, and then assess the attributes as described on the ballot. Between samples, the panelists were instructed to have a cracker and then to rinse with water to cleanse their palates.

After sensory, the data was collated in Excel and processed using analysis of variance (ANOVA) with a mixed model (including the factors panelist, product, and the corresponding two-way interaction), which was determined with XLSTAT 2020.1.1 (Addinsoft, New York, NY, USA) (Table S5). Significant product effects were observed for all of the attributes except for aftertaste duration. Fisher Least Significant Difference (LSD) means comparisons were then determined for each attribute to observe the significant differences between the 
samples for each of the attributes (Table S6). The least-square means were then used for further data analysis and comparison with the chemical results.

\subsection{Statistical Analysis}

Analysis of variance (ANOVA), using production technique as a factor and an $\alpha=0.05$, and Fisher's least significant difference (LSD) means comparisons were determined using XLSTAT 2020.1.1 (Addinsoft, New York, NY, USA) to compare the differences between the analytical results of the different NAB production techniques. Pearson correlation analysis and multi-factor analysis (MFA) were carried out using XLSTAT 2020.1.1 (Addinsoft, New York, NY, USA) to compare the chemical and sensory results.

\section{Results and Discussion}

3.1. Investigating the Effect of Production Techniques on the Basic/Physiochemical Chemistry of the Different NABs

From a legal perspective, ethanol content is the most important analytical parameter when considering NAB quality. According to German legislation, the ethanol content of NAB must not exceed $0.5 \% \mathrm{ABV}$, while NAB labeled as " 0.0 " must be $<0.05 \% \mathrm{ABV}$. Amongst the selected products four beers ( $\mathrm{C} 1, \mathrm{C} 2, \mathrm{M} 1$, and V2) were labeled as " 0.0 " NAB. The ethanol content of these products ranged from $0.01 \% \mathrm{ABV}$ to $0.04 \% \mathrm{ABV}$ (Table 1 ). The remaining $16 \mathrm{NABs}$ ranged between $0.08 \% \mathrm{ABV}$ and $0.43 \% \mathrm{ABV}$. These values are in line with the values reported in previous studies which have also investigated pilsner-style NABs $[13,15,18]$. The NABs produced by restricted fermentation in this study were the group of NABs with the lowest ethanol content on average, ranging from $0.1 \% \mathrm{ABV}$ to $0.25 \% \mathrm{ABV}$. This illustrates that restricted fermentation is a suitable technique to limit ethanol formation, but as will be discussed later, the effect of this treatment on NAB quality might still be a concern. In this study, the NABs produced using MI yeasts, from physical dealcoholization, and from combined/blended treatments tended to have higher ABV on average (i.e., having mean ABVs of $0.39 \%, 0.31 \%$, and $0.36 \%$ respectively after excluding $0.0 \% \mathrm{NAB})$.

The composition of the residual extract (i.e., concentration of dextrins and fermentable carbohydrate levels) varied significantly amongst the different NAB production types, whereas the protein content did not vary significantly (one-way ANOVA based on technique, $p<0.05$, data not shown) (Figure $1 \mathrm{~A}$ and Table 1 ). In agreement with previously reported results [13], NAB made with RF and with the usage of MI yeast contained higher levels of real extract (i.e., 5.6-7.9 g/100 g) and fermentable carbohydrates (i.e., 3.64-4.98 g/100 mL). In addition, in agreement with Schmelzle, Lindemann, and Methner [13], with the exception of $\mathrm{V} 2$, the NAB produced through vacuum distillation treatments were low in real extract (i.e., 3.7-5.3 g/100 g) and contained very low or even nondetectable levels of fermentable carbohydrates (i.e., $<0.1 \mathrm{~g} / 100 \mathrm{~mL}-1.16 \mathrm{~g} / 100 \mathrm{~mL}$ ). The same was true for M1, a " $0.0 \mathrm{NAB}$ " which was the only NAB tested produced using membrane dealcoholization. This NAB had one of the lowest real extracts in the sample set and contained no detectable amounts of fermentable carbohydrates. Consequently, it also had the lowest calorie content of the NABs tested. 
A.)

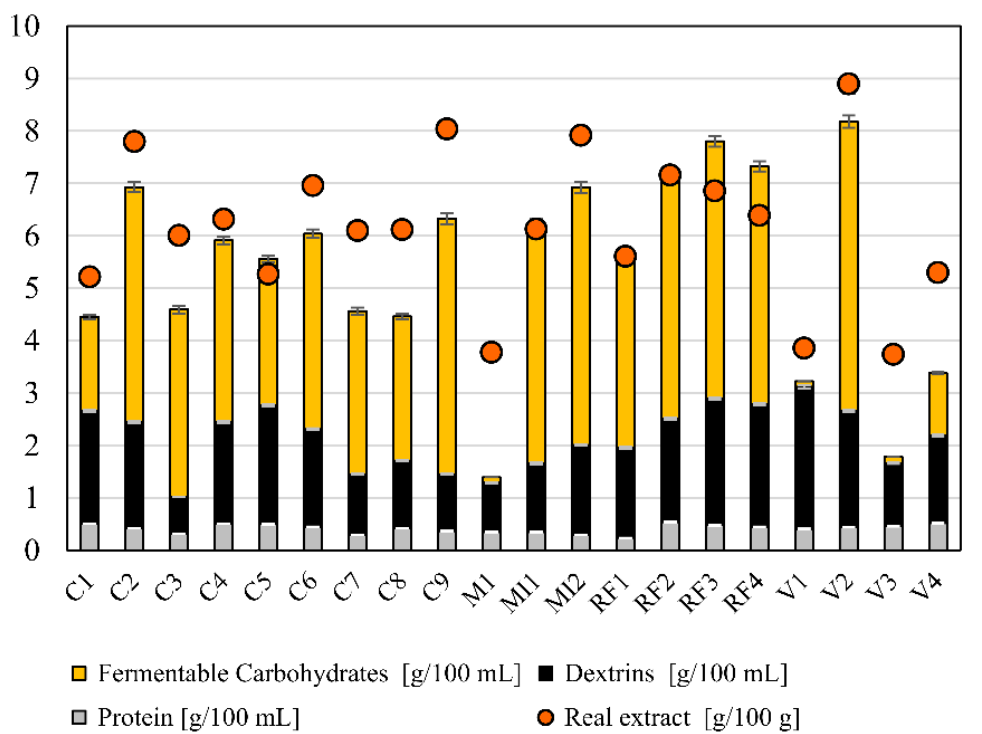

B.)

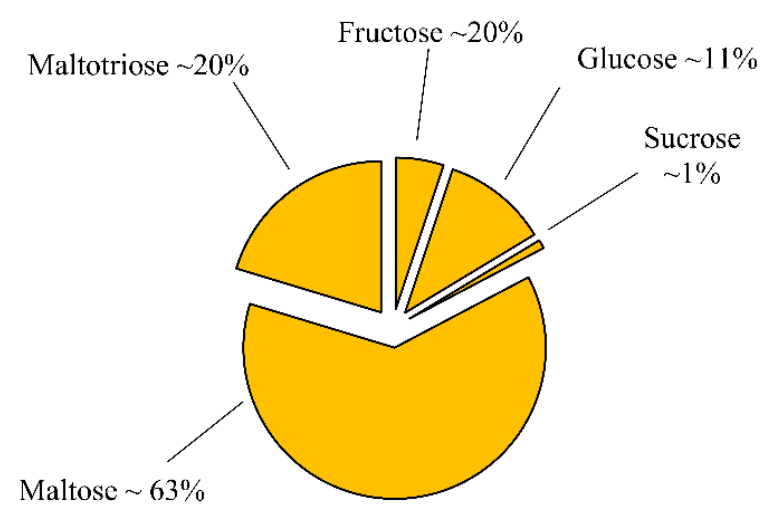

Figure 1. (A) The composition of protein, dextrins. and fermentable carbohydrates and their relationship to residual extract. (B) The average percentage for each individual fermentable carbohydrate (i.e., maltose, maltotriose, fructose, sucrose, and glucose) contribute to the total fermentable carbohydrate profile amongst the different NABs. Error bars are calculated for each measurement and represent $2 \times$ the reported $\%$ RSD.

Across all samples tested, the calories range from $54 \mathrm{~kJ} / 100 \mathrm{~mL}$ (M1) to $141 \mathrm{~kJ} / 100 \mathrm{~mL}$ (V2). Previous research has shown that health and well-being are some of the main factors motivating consumers choose to drink NAB [1,15]. Therefore, both ABV and calorie content are important considerations for designing and/or marketing NAB. When considering the percent contribution of each carbohydrate, the profiles of fermentable carbohydrates were generally similar across the NABs evaluated in this study (Figure 1B). On average, maltose and maltotriose accounted for approximately $83 \%$ of the total fermentable sugar profile in the NABs tested. However, in agreement with the extract values, significantly lower concentrations of the individual carbohydrates were observed in the physically dealcoholized samples (one-way ANOVA based on technique, $p<0.05$, data not shown). The NABs produced with MI yeast yielded the most unique fermentable carbohydrate profiles because they contained lower levels of glucose but the highest concentrations of sucrose, maltose, and maltotriose. These observations also agree with prior studies $[13,18]$ that have investigated the fermentable carbohydrate profile of pilsner-style NABs. Overall, the importance of maltose and maltotriose to the fermentable carbohydrate profile was expected because all the NAB in this study were produced with $100 \%$ malt and without any added sugar/adjuncts (i.e., wheat, oats, etc.). The use of natural artificial sweeteners (i.e., erythritol, stevia, xylitol, monk fruit, etc.) is forbidden for NABs made in Germany due to the German purity law. However, these products could also be explored by brewers outside of Germany who want to reduce the caloric content of their NAB while still maintaining a balanced taste profile [15].

The basic chemistry of V2, also a "0.0 NAB", is particularly unique (Table 1 ). Unlike the other NABs processed through vacuum distillation and when compared to the other pilsner type NABs tested, V2 had the highest residual extract, fermentable carbohydrate concentrations, calorie content, and $\mathrm{pH}$. Based on the information provided by the manufacturer. V2 was produced by performing vacuum distillation on a beer that was high in extract, fermentable carbohydrates, and $\mathrm{pH}$, instead of dealcoholizing a fully fermented pilsner beer. The product formulation and mashing regime of this product were more complex. One possible route for obtaining a NAB with these characteristics is the usage of a mashing 
regime that limits the formation of fermentable sugars and/or by limiting/arresting fermentation. This finding agrees with Ramsey, Yang, Fisk, and Ford [18] who also suggested that pre-processing factors were key considerations in the resulting flavor profiles of NAB. Similarly, although not tested in this study, using some percentage(s) of unique adjuncts (i.e., rye, wheat, unmalted barley, corn, etc.) in grist bills could also be an approach to develop NABs with unique aroma, taste, and mouthfeel [28].

The bitterness units also varied between the different NABs tested. MI2, the IPA, had the highest analytical bitterness (38 IBU) followed by V1 and V4 with each 33 IBU, while C8 had the lowest analytical bitterness of 19 IBU. Across all samples, the mean was $24 \mathrm{IBU}$, which is in line with previously reported values for pilsner-style NAB $[13,15,18]$. Additionally, across the samples tested, color, carbonation, and $\mathrm{pH}$ also varied and agreed with the values reported in previous studies $[13,15,18]$. However, these deviations were more likely related to intended product-specific features than to a specific production technique (Table 1). In 18 of 20 samples, beer color was below $10 \mathrm{EBC}$, which is in line with the color specifications for pilsner-style beer $[13,15,18]$. Exceptions were C9 and MI2, with the latter being the non-alcoholic IPA used as the hoppy reference.

Carbonation ranged from 4.7 to $5.7(\mathrm{~g} / \mathrm{L})$. When compared to the other production techniques, the RF treatments in this study were significantly lower in carbonation on average $(\sim 4.8 \mathrm{~g} / \mathrm{L})$ (one-way ANOVA based on technique, $p<0.05$, data not shown). From a technological point of view, this finding might not be surprising, but from a quality perspective, it remains questionable why no adjustment of carbonation was performed. Although the sensorial impact of carbonation was not assessed in this study, carbonation is a key consideration in the design of NABs and previous research found consumers to be more satisfied with NABs that were fizzier/more tingling and that had higher $\mathrm{CO}_{2}$ concentrations [15]. In addition, it has been shown that $\mathrm{NABs}$ with higher $\mathrm{CO}_{2}$ concentrations were also perceived as less "beer-like" [16]. In Germany, brewers must legally indicate if they add exogenous carbon dioxide to the ingredient list of their products. Therefore, not wanting to report an additional ingredient could be one possible explanation as to why German brewers are choosing not to adjust $\mathrm{CO}_{2}$ levels.

Foam stability values ranged from 101 to $123 \mathrm{~s}$ (Table S1). When comparing the NABs within each production technique there existed NABs with high and with low foam stability but NABs that were physically dealcoholized (i.e., vacuum distillation and membrane filtration) trended lower. So, recipe and/or post-process-related compositional factors appear more important than the production technology on foam stability.

\subsection{Evaluating the Impact of Production Technique on the Volatile Chemistry of the Different $N A B S$}

In this study, a broad spectrum of volatile compounds (i.e., aldehydes, hop-derived terpenes/terpenoids, esters, and fermentation by-products) was analyzed. Overall large concentration ranges were observed for most of the volatiles amongst the NABs made from different production techniques. The concentration ranges of the volatile analytes measured were in line with what has been previously observed in NAB $[15,16]$. The concentrations of fermentation by-products (i.e., acetaldehyde, acetate esters, higher alcohols, and ethyl esters) were low in a majority of the NABs tested and for most of the analytes the results were in the range or below $1 \mathrm{mg} / \mathrm{L}$. Exceptions from this were 3-methyl-1-butanol and phenyl ethanol, which were the two-primary fermentation-derived alcohols observed in the NABs tested (Table S2).

The volatile profile of $\mathrm{C} 1$ is particularly unique because, as previously mentioned, this NAB had a natural aroma extract added to it. Interestingly, the fermentation byproduct spectrum of $\mathrm{C} 1$ is more similar to what one would generally expect in an alcoholic pilsner type beer. For instance, C1 contained $4 \mathrm{mg} / \mathrm{L}$ ethyl acetate, $31 \mathrm{mg} / \mathrm{L}$ 3-methyl-1butanol, and $19 \mathrm{mg} / \mathrm{L}$ of phenyl ethanol, whereas alcoholic pilsner beer has been shown to contain $\sim 8-32 \mathrm{mg} / \mathrm{L}$ ethyl acetate [29], $50 \mathrm{mg} / \mathrm{L} 3$-methyl-1-butanol [30], and $\sim 18 \mathrm{mg} / \mathrm{L}$ of phenyl ethanol [30]. However, compared to its alcoholic counterpart (data not shown), 
it is clear that the aroma addition of $\mathrm{C} 1$ did not target to add equivalent concentrations of the fermentation by-products and is in the range of $50 \%$ or less for most volatiles. This is because it has been shown that the amount of ethanol has an impact on the release and perception of volatiles in NAB/alcoholic beer [31] and this should be taken into consideration when brewers choose to use aroma extracts.

When considering the analytical precision (\%RSD) and concentration range, the concentrations of ethyl esters detected in this study (Table S4) fall well below previously reported thresholds of these compounds [32]. Therefore, it is likely that these esters are playing a limited role in German NAB pilsner beer flavor. However, the concentrations of ethyl esters in $\mathrm{C} 1$ were also unique to the other NABs. In general, the concentrations of ethyl butyrate $(15 \mu \mathrm{g} / \mathrm{L})$, ethyl hexanoate $(62 \mu \mathrm{g} / \mathrm{L})$, and ethyl octanoate $(14 \mu \mathrm{g} / \mathrm{L})$, were all detected in levels of $>5 \mu \mathrm{g} / \mathrm{L}$ in $\mathrm{C} 1$. However, this was not the case for the majority of the other NABs tested. One could assume that ethyl butyrate and ethyl hexanoate were included in the natural aroma added to this beer because $\mathrm{C} 1$ contained comparably high concentrations of ethyl butyrate and ethyl hexanoate, whereas the concentration of ethyl octanoate was in the range of most other NABs. The only other NABs that contained detectable levels of all three ethyl esters were M1 and V3, while for the majority of the other NABs, only ethyl octanoate was found.

As reported previously [25], the concentrations of staling aldehydes in NAB are commonly higher than compared to the concentrations observed in beer. In this study, the concentrations of aldehydes varied significantly amongst the NABs and occurred in concentrations below previously reported sensory thresholds [33] (Table S3). The concentrations measured are also in agreement with previously reported values [15,17]. Across the samples tested, furfural was the primary aldehyde and ranged from $31 \mu \mathrm{g} / \mathrm{L}$ (V4) to $250 \mu \mathrm{g} / \mathrm{L}$ (M1) (Table S3). The Strecker aldehydes 3-methylbutanal, 2-methylpropanal, phenylacetaldehyde, methional, and 2-methylpropanal ranged from $\sim 1 \mu \mathrm{g} / \mathrm{L}$ to $\sim 60 \mu \mathrm{g} / \mathrm{L}$, while the (unsaturated) linear aldehydes were typically at concentrations $<1 \mu \mathrm{g} / \mathrm{L}$ (Table S3). Compared to the other production techniques, membrane treatment resulted in significantly higher concentrations of furfural, methional, phenylacetaldehyde, pentanal, 3-methylbutanal, and 2-methylbutanal, whereas combined and vacuum treatments resulted in significantly lower concentrations of 2-methylbutanal and pentanal (one-way ANOVA based on technique, $p<0.05$, data not shown).

As mentioned in the introduction, numerous studies $[14,15,18,19,34]$ have shown that adding hops at various stages throughout the brewing process can be an effective approach to positively alter the sensory profile of NAB. For the NABs evaluated, 75\% of the products contained detectable concentrations of hop-related volatiles (Table S4). Linalool has previously been defined as a key hop volatile contributing to pilsner-style beer flavor [30] and has a reported flavor threshold of $\sim 5 \mu \mathrm{g} / \mathrm{L}$ [35]. Eight out of 20 (i.e., C9, MI2, C5, C4, RF2, RF5, RF1, and C6) of the samples tested contained linalool above its threshold. These eight NABs were also the beers that contained detectable levels of most of the other terpenes and terpenoids measured. Not surprisingly, the non-alcoholic IPA, MI2, contained the highest levels of most hop aroma compounds. However, C4, C5, and C9 were also rich in many terpenes and terpenoids and contained high levels of hop-derived 2-methylbutyl isobutyrate (64-307 $\mu \mathrm{g} / \mathrm{L})$. This suggests that novel hopping techniques, such as late and dry-hopping, were used in the production of these NABs. Further, even though this manuscript is concerned with pilsner type NAB and also does not specifically aim to discuss the impact of maltose intolerant yeast on hop flavor during NAB fermentation, it is very interesting to note that MI2 (i.e., the NA IPA produced with MI yeasts) contained high levels of citronellol $(39 \mu \mathrm{g} / \mathrm{L})$. Some yeast strains have been shown to convert geraniol into citronellol during fermentation, which can increase the citrusy flavor of beer [35]. Therefore, the ability of MI yeasts in modifying hop-derived volatiles during fermentation could be interesting to investigate in the future.

Previously, hop aroma and fruity character of NABs were shown to drive consumer liking, while DMS was shown to increase the perception of "beer likeness" in NAB [15,16]. 
Overall, when considering DMS concentrations in pilsner-style NAB made from 100\% malt bills (Table S4), the samples might simply be divided into those that contained DMS (29 to $54 \mu \mathrm{g} / \mathrm{L}$ ) and those that did not contain detectable levels of DMS. Beers that did not contain DMS at a concentration greater than $10 \mu \mathrm{g} / \mathrm{L}$ were the vacuum dealcoholized NAB $\mathrm{V} 1-\mathrm{V} 4$, as well as $\mathrm{C} 1$ and $\mathrm{C} 7$ which were produced using combined treatments. Given the low boiling point of DMS and the absence of DMS in vacuum dealcoholized beers, one can assume that $\mathrm{C} 1$ and $\mathrm{C} 7$ are made with a major share of vacuum dealcoholized beer. If desired, it is possible that blending a NAB made from restricted fermentation might be a suitable approach for increasing "beer likeness" in NABs made via vacuum distillation.

Previously, NABs with higher skunk aroma quality (also known as "lightstruck") were not highly preferred by consumers [15] but were perceived to be more beer-like [16]. Although they did not have analytical data, the authors of these studies hypothesized that the increase in the skunk quality in the NABs evaluated was due to the increase of 3-methylbut-2-ene-1-thiol (3-MBT)-3-MBT can result from either the direct or indirect irradiation of iso- $\alpha$-acids as shown to be the case in alcoholic pilsners [36]. Therefore, in this study, the 3-MBT concentration was evaluated in the NABs. The 3-MBT concentration was the highest in V3 at $23.8 \mathrm{ng} / \mathrm{L}$ and the four NABs packaged in green bottles had an average of 13.3 (ng/L), whereas the average 3-MBT content for the rest of the NABs was $4.5 \mathrm{ng} / \mathrm{L}$. Given the sensory detection threshold of 3-MBT is 4-7 $\mathrm{ng} / \mathrm{L}$ [37], this is clear analytical evidence that package type can also have an impact on the NAB aroma profile a consumer is going to experience. If this is an undesired characteristic, the implementation of reduced hop acids and/or light-filtering packaging in brown bottles and/or cans has been shown previously to reduce the formation of 3-MBT in alcoholic pilsners [37].

\subsection{Using Multiple Factor Analysis to Elucidate How Changes in Chemistry Which Are Influenced by Production Technique Result in Changes to NAB Sensory}

Multiple factor analysis (MFA) was performed with the results of the sensory (Table S6) and chemical (Tables 1 and S1-S4) analyses. Based on the active groups used for the analysis, the MFA allowed for distances between each of the NABs to be calculated and visualized by considering each qualitative (i.e., treatments) and quantitative (i.e., sensory, esters, hop volatiles, staling aldehydes, aldehydes/alcohols/esters, sugars, glycerol, ABV, IBU, DMS, $3 \mathrm{MBT}, \mathrm{CO}_{2}, \mathrm{pH}$, protein, and dextrins) factor.

The MFA observation factor chart of the first two components highlights the impact of production technique as well as the influence of pre- and post-processing decisions amongst the different NAB samples (Figure 2A). The NABs produced primarily though restricted fermentation sit in the bottom right-hand quadrant of the plot. Conversely, except for V2, the beers produced via physical dealcoholization techniques are in the left-hand quadrants (i.e., membrane filtration (M) and vacuum distillation (V)). NABs produced using maltose intolerant yeast as well as those that were dry-hopped sit in the top of the upper right-hand quadrant, while the NABs produced through combined/blended treatments sit both in the bottom of the upper right-hand quadrant as well as the top of the lower right-hand quadrant. To aid in visualization, NABs packaged in green bottles are indicated by green circles and 0.0 NABs are indicated by the inclusion of the text $0.0 \%$. Generally, this supports the finding by Schmelzle, Lindemann, and Methner [13] that the choice of production technique is a critical determinative in the resulting flavor profile of NAB. 


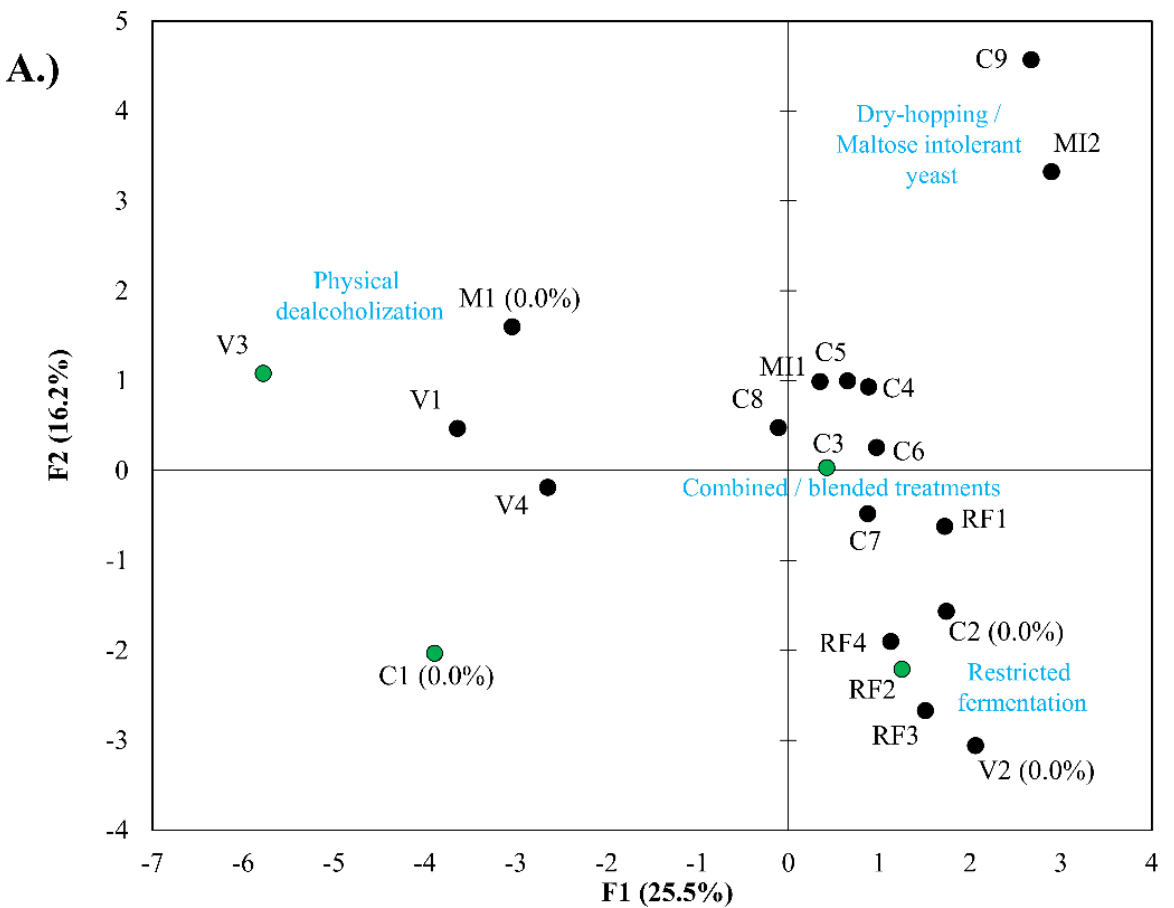

B.)

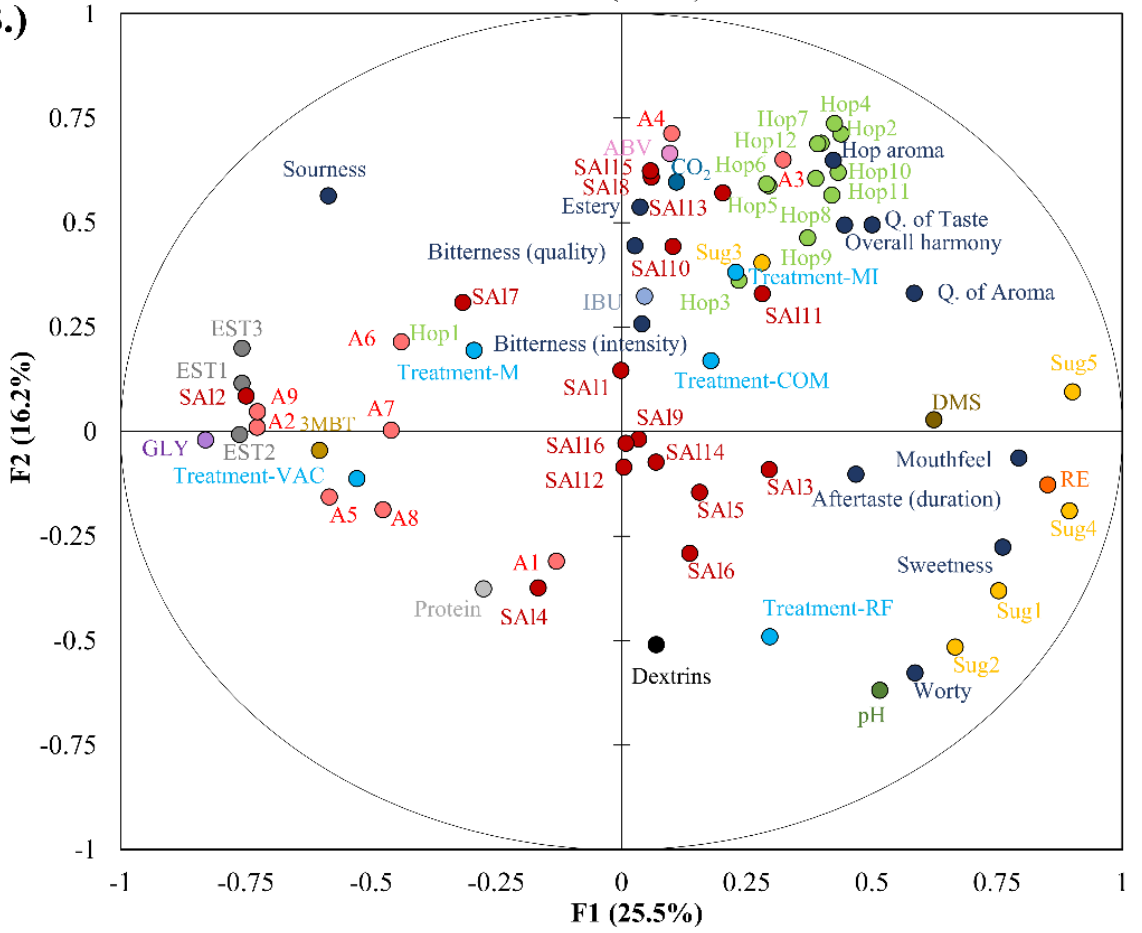

Figure 2. To observe the differences between the different pilsner style NABs, multiple factor analysis (MFA) was performed. (A) The observation factor chart showing the NABs in the MFA space. The sample labels are reported in Table 1 and the different treatments are abbreviated as follows: use of Maltose-intolerant yeast (MI), Restricted fermentation (RF), Membrane dealcoholization (M), Vacuum dealcoholization (V), Combined treatments (C). (B) The correlation circle map of the MFA with the qualitative (i.e., treatments (turquoise)) and quantitative (i.e., sensory (dark blue), esters (dark gray), hop volatiles (light green), staling aldehydes (dark red), aldehydes/alcohols/esters (light red), sugars (light orange), glycerol (purple), ABV (pink), IBU (light gray blue), DMS (dark brown), 3MBT (light brown), $\mathrm{CO}_{2}$ (dark gray blue), $\mathrm{pH}$ (dark green), protein (light gray), and dextrins (black)) factors. During the initial computations, only the quantitative factors were considered. The codes for the factors are defined in Tables 1-3. 
Table 2. Pearson correlation coefficients between sensory and volatile analyses.

\begin{tabular}{|c|c|c|c|c|c|c|c|c|c|c|c|c|c|}
\hline Variables & $\begin{array}{c}\text { MFA } \\
\text { Abbrev. }\end{array}$ & Aroma & Taste & $\begin{array}{l}\text { Hop } \\
\text { Aroma }\end{array}$ & Sweet & Sour & $\begin{array}{l}\text { Bitter } \\
\text { (int.) }\end{array}$ & $\begin{array}{l}\text { Bitter } \\
\text { (qual.) }\end{array}$ & Estery & Worty & Mouthfeel & $\begin{array}{l}\text { Aftertaste } \\
\text { (Duration) }\end{array}$ & $\begin{array}{l}\text { Overall } \\
\text { Harmony }\end{array}$ \\
\hline$\stackrel{2-}{2-}$ & Sal1 & -0.28 & -0.25 & 0.18 & 0.04 & 0.28 & -0.15 & -0.08 & 0.26 & -0.15 & -0.25 & 0.00 & -0.16 \\
\hline Ethyl nicotinate & Sal2 & -0.34 & -0.28 & -0.16 & -0.61 & 0.39 & -0.10 & 0.17 & 0.23 & -0.61 & -0.61 & -0.16 & -0.15 \\
\hline 2-Methylbutanal & Sal3 & 0.21 & 0.07 & 0.30 & 0.25 & -0.07 & -0.22 & 0.15 & 0.18 & 0.17 & 0.03 & 0.13 & 0.08 \\
\hline 3-Methylbutanal & Sal4 & -0.13 & -0.17 & 0.01 & -0.03 & -0.08 & -0.39 & 0.13 & 0.36 & -0.10 & -0.30 & -0.20 & -0.07 \\
\hline Pentanal & Sal5 & 0.02 & -0.15 & 0.11 & 0.26 & -0.02 & -0.38 & 0.06 & 0.25 & 0.21 & -0.04 & -0.01 & -0.10 \\
\hline Hexanal & Sal6 & -0.04 & -0.19 & -0.01 & 0.25 & -0.14 & -0.40 & 0.08 & 0.12 & 0.28 & 0.01 & -0.06 & -0.14 \\
\hline 2-Furfural & Sal7 & 0.03 & 0.08 & -0.04 & -0.37 & 0.34 & -0.39 & 0.38 & 0.19 & -0.31 & -0.49 & -0.55 & 0.11 \\
\hline Heptanal & Sal8 & 0.25 & 0.31 & 0.56 & -0.09 & 0.50 & 0.00 & 0.38 & 0.66 & -0.38 & -0.08 & -0.21 & 0.29 \\
\hline Methional & Sal9 & -0.01 & -0.08 & -0.05 & 0.06 & 0.25 & -0.41 & -0.04 & 0.09 & 0.13 & -0.10 & -0.20 & -0.18 \\
\hline Octanal & Sal10 & 0.25 & 0.35 & 0.44 & 0.01 & 0.01 & 0.20 & 0.58 & 0.47 & -0.30 & -0.01 & -0.26 & 0.44 \\
\hline Benzaldehyde & Sal11 & 0.20 & 0.14 & 0.24 & 0.17 & 0.08 & -0.23 & 0.19 & 0.26 & 0.08 & 0.02 & -0.01 & 0.12 \\
\hline Phenylacetaldehyde & Sal12 & 0.10 & 0.01 & -0.11 & -0.01 & 0.02 & -0.57 & 0.30 & -0.01 & 0.11 & -0.26 & -0.28 & -0.02 \\
\hline Nonanal & Sal13 & 0.38 & 0.54 & 0.67 & 0.02 & 0.05 & 0.30 & 0.69 & 0.56 & -0.40 & 0.12 & -0.21 & 0.64 \\
\hline E-2-Nonenal & Sal14 & 0.19 & 0.22 & 0.08 & -0.01 & -0.31 & 0.01 & 0.49 & -0.01 & -0.05 & -0.05 & -0.27 & 0.34 \\
\hline Decanal & Sal15 & 0.28 & 0.47 & 0.55 & -0.15 & 0.21 & 0.24 & 0.40 & 0.60 & -0.52 & 0.00 & -0.14 & 0.53 \\
\hline $\begin{array}{c}\text { E,E-2,4- } \\
\text { Decadienal }\end{array}$ & Sal16 & 0.22 & 0.28 & -0.02 & -0.06 & -0.33 & -0.16 & 0.55 & 0.07 & -0.08 & 0.07 & -0.33 & 0.38 \\
\hline$-\overline{\alpha-P i n e n e}-$ & $\overline{\mathrm{H}} \overline{\mathrm{p}} \overline{1}$ & ${ }_{-0.07} \overline{-}$ & $-{ }_{-0} . \overline{0} 5^{-}$ & ${ }^{-}{ }^{-} 0 . \overline{1} 3^{-}$ & ${ }^{-} 0 . \overline{3} 3-$ & $\overline{0.53}$ & $\overline{-0.42}$ & $\overline{0} . \overline{0}$ & $\overline{0} . \overline{13}$ & $-\overline{-0 . \overline{1} 9^{-}}$ & ${ }_{-} \overline{0.35}$ & $-\overline{0} \cdot \overline{41}$ & $-\overline{-0} \cdot \overline{17}^{-}$ \\
\hline Myrcene & Hop2 & 0.55 & 0.58 & 0.92 & 0.21 & 0.12 & 0.32 & 0.43 & 0.70 & -0.30 & 0.29 & 0.28 & 0.68 \\
\hline $\begin{array}{l}\text { 2-Methylbutyl } \\
\text { isobutyrate }\end{array}$ & Hop3 & 0.25 & 0.41 & 0.56 & 0.10 & 0.05 & 0.32 & 0.44 & 0.29 & -0.20 & 0.28 & -0.03 & 0.44 \\
\hline Limonene & Hop4 & 0.49 & 0.51 & 0.87 & 0.23 & 0.21 & 0.27 & 0.30 & 0.70 & -0.26 & 0.23 & 0.25 & 0.56 \\
\hline cis-Linalool oxide & Hop5 & 0.18 & 0.21 & 0.50 & 0.17 & 0.32 & 0.11 & 0.02 & 0.53 & -0.16 & 0.08 & 0.02 & 0.25 \\
\hline $\begin{array}{l}\text { trans-Linalool } \\
\text { oxide }\end{array}$ & Hop6 & 0.18 & 0.21 & 0.51 & 0.16 & 0.32 & 0.11 & 0.03 & 0.53 & -0.17 & 0.08 & 0.01 & 0.25 \\
\hline Linalool & Hop7 & 0.37 & 0.39 & 0.75 & 0.22 & 0.25 & 0.22 & 0.17 & 0.65 & -0.22 & 0.17 & 0.18 & 0.44 \\
\hline Terpineol & Hop8 & 0.38 & 0.49 & 0.80 & 0.23 & 0.15 & 0.41 & 0.28 & 0.47 & -0.18 & 0.30 & 0.17 & 0.46 \\
\hline Citronellol & Hop9 & 0.60 & 0.56 & 0.77 & 0.18 & -0.07 & 0.32 & 0.35 & 0.45 & -0.18 & 0.28 & 0.50 & 0.58 \\
\hline Nerol & Hop10 & 0.59 & 0.56 & 0.88 & 0.22 & 0.05 & 0.35 & 0.31 & 0.61 & -0.23 & 0.27 & 0.47 & 0.60 \\
\hline Geraniol & Hop11 & 0.56 & 0.52 & 0.85 & 0.22 & 0.04 & 0.29 & 0.33 & 0.60 & -0.24 & 0.23 & 0.42 & 0.59 \\
\hline Humulene & Hop12 & 0.49 & 0.47 & 0.82 & 0.22 & 0.16 & 0.24 & 0.25 & 0.66 & -0.24 & 0.19 & 0.33 & 0.54 \\
\hline$-\overline{\text { Ethyl }} \overline{\text { butyraate }}-$ & $-\overline{\mathrm{EST} 1}-$ & $=0 . \overline{2} 0^{-}$ & $-0 . \overline{1} 6^{-}$ & $=0 . \overline{1} 8^{-}$ & $=0 . \overline{4} 7$ & $\overline{0} . \overline{42}$ & $=0.13$ & $0.1 \overline{2}$ & $\overline{0} . \overline{17}-$ & $-=0 . \overline{4} 4-$ & $=\overline{0.55}$ & $-\overline{0} . \overline{42}$ & $-\frac{0 . \overline{2} 1}{-0}-$ \\
\hline Ethyl hexanoate & EST2 & -0.23 & -0.16 & -0.20 & -0.47 & 0.24 & -0.16 & 0.16 & 0.26 & -0.47 & -0.51 & -0.39 & -0.15 \\
\hline Ethyl octanoate & EST3 & -0.27 & -0.16 & -0.22 & -0.67 & 0.47 & 0.20 & 0.07 & -0.10 & -0.54 & -0.55 & -0.30 & -0.18 \\
\hline$-{ }_{\mathrm{DM}} \overline{\mathrm{S}}--$ & ${ }^{-} \overline{\mathrm{DMS}}{ }^{-}$ & $\overline{0} . \overline{34}-$ & $-\overline{0.39}-$ & $\overline{0} . \overline{23}-$ & $\overline{0} . \overline{22}-$ & $-\overline{-}-\overline{3} 2^{-}$ & $-\overline{0} \overline{0} 8^{-}$ & $-\overline{-0} . \overline{0} 7^{-}$ & ${ }^{-}-0 . \overline{0} 8^{-}$ & $\overline{0} . \overline{0}$ & $-0.35^{-}$ & $\overline{0.33}$ & $\overline{0.1 \overline{6}}--$ \\
\hline - Ācetā̄ēhyde & $-\bar{A} \overline{1}-$ & $=0 . \overline{4} 2^{-}$ & $-\frac{-}{-3} 5^{-}$ & $-0 . \overline{3} 3^{-}$ & $=0 . \overline{2} 9$ & $-{ }_{-0.03}-$ & $=\overline{-0.07}$ & $-\overline{-0.15}-$ & $-=0 . \overline{3} 3^{-}$ & $\overline{0} .0 \overline{3}$ & $=\overline{0.2 \overline{4}}$ & $\overline{0.13}$ & $-\frac{0.34}{-0}-$ \\
\hline Ethyl acetate & $\mathrm{A} 2$ & -0.21 & -0.14 & -0.17 & -0.45 & 0.21 & -0.12 & 0.15 & 0.27 & -0.48 & -0.49 & -0.33 & -0.13 \\
\hline 1-Propanol & $\mathrm{A} 3$ & 0.24 & 0.29 & 0.57 & 0.15 & 0.31 & 0.13 & 0.09 & 0.5 & -0.20 & 0.10 & 0.03 & 0.33 \\
\hline Isobutanol & $\mathrm{A} 4$ & 0.23 & 0.44 & 0.46 & -0.25 & 0.40 & -0.08 & 0.50 & 0.36 & -0.42 & -0.09 & -0.29 & 0.37 \\
\hline Isoamyl acetate & A5 & -0.23 & -0.18 & -0.18 & -0.33 & 0.10 & -0.36 & 0.12 & 0.48 & -0.41 & -0.41 & -0.34 & -0.11 \\
\hline $\begin{array}{l}\text { 2-Methyl-1- } \\
\text { Butanol }\end{array}$ & A6 & -0.03 & 0.09 & 0.00 & -0.46 & 0.35 & -0.48 & 0.30 & 0.58 & -0.52 & -0.43 & -0.42 & 0.06 \\
\hline $\begin{array}{l}\text { 3-Methyl-1- } \\
\text { Butanol }\end{array}$ & A7 & -0.10 & -0.02 & -0.05 & -0.36 & 0.16 & -0.45 & 0.22 & 0.58 & -0.46 & -0.41 & -0.35 & 0.01 \\
\hline Phenethyl acetate & $\mathrm{A} 8$ & -0.26 & -0.21 & -0.15 & -0.28 & 0.05 & -0.33 & 0.07 & 0.50 & -0.38 & -0.35 & -0.26 & -0.10 \\
\hline Phenyl ethanol & A 9 & $=0.53$ & -0.59 & -0.32 & $=0.60$ & $\underline{0.56}$ & 0.27 & -0.25 & -0.16 & -0.47 & -0.62 & $-\underline{0.11}$ & -0.45 \\
\hline $\begin{array}{c}\text { 3-M̄ethyl- } \overline{2}- \\
\text { butene-1-thiol }\end{array}$ & $3 \mathrm{MBT}$ & -0.32 & -0.25 & -0.09 & -0.32 & $\overline{0.17}$ & $0 . \overline{30}$ & -0.09 & -0.07 & -0.29 & -0.34 & $-\overline{-}-\overline{12}$ & -0.23 \\
\hline
\end{tabular}

Values in bold are different from 0 with a significance level alpha $=0.05$ and significant positive and negative correlations highlighted by green and red respectively. DMS-Dimethyl sulfide.

The correlation circle (Figure 2B) can then be used to observe the relationships amongst the different quantitative and qualitative variables as well as the samples. Variables that are highly correlated are grouped, while variables negatively correlated occur on opposite sides of the plot. For example, worty, sweet, and aftertaste duration occur in the bottom right-hand quadrant, indicating that NABs produced only through restricted fermentation generally had longer aftertastes and were perceived to be the most worty and sweet (Figure 2B and Table S6). These findings are also in agreement with Schmelzle, Lindemann, and Methner [13] which showed that products produced by restricted fermentations had strong wort-like aromas and sweet tastes. Analytically, these NABs generally had the highest $\mathrm{pH}$, the highest residual extracts (i.e., $\mathrm{RE}$ ), and contained the highest concentrations of dextrins as well as Sug1, Sug2, Sug4, SA13, SA15, and SA16 (corresponding to fructose, glucose, maltose, nonanal, decanal, and E,E-2,4-decadienal). Interestingly, V2 also sits in this region, and as discussed previously this is likely due to its unique mash/wort profile. As shown previously [25], the concentration of nonanal, decanal, and E,E-2,4-decadienal tend to be very low in fully fermented beer, while wort contains detectable levels of all three volatiles. 
Table 3. Pearson correlation coefficients between sensory and physicochemical analyses.

\begin{tabular}{|c|c|c|c|c|c|c|c|c|c|c|c|c|c|}
\hline Variables & $\begin{array}{c}\text { MFA } \\
\text { Abbrev. }\end{array}$ & Aroma & Taste & $\begin{array}{c}\text { Hop } \\
\text { Aroma }\end{array}$ & Sweet & Sour & $\begin{array}{l}\text { Bitter } \\
\text { (int.) }\end{array}$ & $\begin{array}{l}\text { Bitter } \\
\text { (qual.) }\end{array}$ & Estery & Worty & Mouthfeel & $\begin{array}{l}\text { Aftertaste } \\
\text { (Duration) }\end{array}$ & $\begin{array}{l}\text { Overall } \\
\text { Harmony }\end{array}$ \\
\hline Aroma & Taste & 1.00 & & & & & & & & & & & \\
\hline Taste & Aroma & 0.88 & 1.00 & & & & & & & & & & \\
\hline Hop aroma & $\begin{array}{c}\text { Hop } \\
\text { aroma }\end{array}$ & 0.48 & 0.58 & 1.00 & & & & & & & & & \\
\hline Sweetness & Sweetness & 0.44 & 0.24 & 0.20 & 1.00 & & & & & & & & \\
\hline Sourness & Sourness & -0.32 & -0.25 & 0.04 & -0.63 & 1.00 & & & & & & & \\
\hline $\begin{array}{l}\text { Bitterness } \\
\text { (intensity) }\end{array}$ & $\begin{array}{l}\text { Bitterness } \\
\text { (intensity) }\end{array}$ & 0.02 & 0.09 & 0.42 & -0.12 & 0.19 & 1.00 & & & & & & \\
\hline $\begin{array}{l}\text { Bitterness } \\
\text { (quality) }\end{array}$ & $\begin{array}{l}\text { Bitterness } \\
\text { (quality) }\end{array}$ & 0.40 & 0.59 & 0.47 & -0.07 & -0.10 & -0.20 & 1.00 & & & & & \\
\hline Estery & Estery & 0.34 & 0.44 & 0.67 & 0.00 & 0.16 & -0.06 & 0.54 & 1.00 & & & & \\
\hline Worty & Worty & 0.20 & -0.05 & -0.34 & 0.74 & -0.62 & -0.26 & -0.36 & -0.53 & 1.00 & & & \\
\hline Mouthfeel & Mouthfeel & 0.65 & 0.59 & 0.23 & 0.75 & -0.61 & 0.06 & 0.06 & 0.00 & 0.60 & 1.00 & & \\
\hline $\begin{array}{l}\text { Aftertaste } \\
\text { (duration) }\end{array}$ & Aftertaste & 0.33 & 0.09 & 0.21 & 0.27 & -0.25 & 0.42 & -0.42 & -0.19 & 0.35 & 0.37 & 1.00 & \\
\hline $\begin{array}{l}\text { Overall } \\
\text { harmony }\end{array}$ & $\begin{array}{c}\text { Overall } \\
\text { harmony }\end{array}$ & 0.72 & 0.86 & 0.68 & 0.23 & -0.30 & 0.02 & 0.74 & 0.57 & -0.19 & 0.45 & -0.06 & 1.00 \\
\hline$--\overline{A B} \bar{V}-$ & ${ }_{-} \overline{A B} \bar{V}-$ & $-0 . \overline{2} 3^{-}$ & $-0 . \overline{4} 0^{-}$ & $-\overline{0.45}-$ & $=0 . \overline{2} 5$ & $\overline{0} \cdot \overline{22}-$ & $-{ }_{0} . \overline{2} 6^{-}$ & $\overline{0.4 \overline{1}}$ & $-\overline{0} .1 \overline{2}-$ & $-0 . \overline{4} 0^{-}$ & $\overline{0.06}-$ & $-\overline{0.1 \overline{3}}-$ & $-\overline{0.4 \overline{5}}-$ \\
\hline $\begin{array}{l}\text { Real } \\
\text { Extract (RE) }\end{array}$ & $\mathrm{RE}$ & 0.45 & 0.35 & 0.32 & 0.81 & -0.62 & -0.04 & -0.04 & 0.14 & 0.52 & 0.75 & 0.39 & 0.40 \\
\hline Fructose & $-{ }^{-} \overline{\text { Sug }} \overline{1}-$ & $0 . \overline{2} 3$ & ${ }^{-} 0 . \overline{1} 7^{-}$ & $-\overline{0.03}-$ & $\overline{0.74}$ & $=\overline{0.68}$ & ${ }_{-} \overline{0.15}$ & ${ }^{-}-\overline{0} . \overline{12}$ & $-\overline{-0 . \overline{1} 1}-$ & $\overline{0} . \overline{6}$ & $\overline{0.69}$ & $-\overline{0.1 \overline{3}}$ & $-\overline{0.1 \overline{8}}$ \\
\hline Glucose & Sug2 & 0.16 & 0.06 & -0.12 & 0.69 & -0.66 & -0.19 & -0.22 & -0.22 & 0.73 & 0.60 & 0.16 & 0.06 \\
\hline Sucrose & Sug3 & 0.52 & 0.46 & 0.68 & 0.16 & -0.08 & 0.25 & 0.33 & 0.42 & -0.18 & 0.19 & 0.46 & 0.52 \\
\hline Maltose & Sug4 & 0.41 & 0.30 & 0.31 & 0.79 & -0.74 & -0.08 & -0.04 & 0.01 & 0.60 & 0.66 & 0.45 & 0.32 \\
\hline Maltotriose & Sug5 & 0.50 & 0.43 & 0.53 & 0.78 & -0.53 & 0.04 & 0.05 & 0.21 & 0.41 & 0.67 & 0.41 & 0.50 \\
\hline$-{ }^{-} \overline{\text { Glycerol }}$ & $-G \overline{G L}-$ & $-\overline{0.53}$ & $-\overline{0.5 \overline{2}}$ & $-\overline{-0 . \overline{39}}{ }^{-}$ & -0.57 & $0 . \overline{55}-$ & $0 . \overline{1} 4^{-}$ & $-\overline{0} . \overline{20}-$ & $-\overline{-}-\overline{1} 0^{-}$ & $-0 . \overline{4} 7^{-}$ & $-\overline{0} . \overline{63}$ & $-\overline{0} . \overline{23}-$ & $-0 . \overline{4} 4$ \\
\hline$---\overline{\mathrm{pH}}-$ & $--\overline{\mathrm{pH}}-{ }^{-}$ & $-0 . \overline{2} 4^{-}$ & $-0.09^{-}$ & $-\overline{-0.05}-$ & $\overline{0.60}-$ & $=0.72$ & $0 . \overline{1} 2^{-}$ & $-\overline{0} \cdot \overline{24}-$ & $-\overline{-0.31}-$ & $-\overline{0.57}-$ & $0.57-$ & $-\overline{0.5 \overline{2}}-$ & $-\overline{0.0 \overline{3}}-$ \\
\hline$---\mathrm{I} \overline{\mathrm{B}} \overline{\mathrm{U}}-$ & $-{ }^{-} \mathrm{I} \overline{\mathrm{B}} \overline{\mathrm{U}}-$ & $0 . \overline{0} 6^{-}$ & ${ }^{-} 0 . \overline{1} 1^{-}$ & $-\overline{0.4 \overline{8}}-$ & -0.12 & $0 . \overline{18}$ & $0 . \overline{86}$ & $-\overline{0} . \overline{05}-$ & $-\overline{-0.08}-$ & $-0 . \overline{2} 8$ & $-\overline{0.08}-$ & $\overline{0.5 \overline{1}}$ & $-\overline{0.1 \overline{0}}-$ \\
\hline$-\overline{\mathrm{CO}}_{2}^{-}-$ & $-\overline{\mathrm{CO}}_{2}^{-}-$ & ${ }_{-}^{-} 0 . \overline{0} 1_{-}^{-}$ & $0 . \overline{1} 2^{-}$ & 0.15 & $=0.08$ & $0 . \overline{46}{ }^{-}$ & $0 . \overline{0} 1_{-}^{-}$ & $-\overline{0.0 \overline{4}}$ & $-\overline{0} .1 \overline{2}$ & $-0 . \overline{1} 6$ & $0.16-$ & $-0 . \overline{20}$ & $\overline{0.1 \overline{7}}-$ \\
\hline$--\overline{\text { Protein }}-$ & $-\bar{P}^{-} \overline{-i n}^{-}$ & $=\overline{0.4 \overline{8}}$ & $-\overline{0} .3 \overline{3}$ & $-\overline{0.15}-$ & $-0 . \overline{1} 4^{-}$ & $=0.08^{-}$ & $\overline{-} \overline{0.0 \overline{9}}$ & $-\overline{0.1 \overline{3}}$ & $-\overline{-0} .03^{-}$ & $-\overline{-0.18}{ }^{-}$ & $-\overline{0} . \overline{9}-$ & $--\overline{0} . \overline{29}-$ & $-\overline{-0.08}-$ \\
\hline${ }^{-}-\overline{\text { Dextrins }}{ }^{-}$ & ${ }^{-} \overline{\text { Dextrins }}{ }^{-}$ & ${ }^{-} \overline{0.2 \overline{3}}$ & $-\overline{0} .3 \overline{5}$ & $-\overline{-0 . \overline{09}}$ & $\overline{0.03}-$ & $=0 . \overline{25}$ & $-0 . \overline{1} 6^{-}$ & $-\overline{0} . \overline{20}$ & $-0 . \overline{2} 1-$ & $-\overline{0.07}-$ & $-\overline{0} . \overline{4}-$ & $-\overline{0.3 \overline{3}}-$ & $-\overline{-0 . \overline{19}}-$ \\
\hline
\end{tabular}

Values in bold are different from 0 with a significance level alpha $=0.05$ and significant positive and negative correlations highlighted by green and red respectively. ABV-Alcohol by volume. IBU-International bitterness units.

In comparison, because sourness is significantly negatively correlated with $\mathrm{pH}$, sourness occurs in the upper left-hand quadrant. Therefore, also in agreement with the findings in Schmelzle, Lindemann, and Methner [13], most of the physically dealcoholized NABs (i.e., V3, V1, M1, and V4) were in the left-hand quadrant. These NABs had the lowest $\mathrm{pHs}$ and were perceived to be sourer (Tables 1 and S6). These samples were also the least harmonious and had some of the lowest aroma and taste intensities (Table S6). Again, this agrees with previous findings showing that only using physical dealcoholization to produce $\mathrm{NAB}$ can lead to a loss and/or imbalance in NAB flavor [4]. Interestingly, both methods of physical dealcoholization (i.e., vacuum distillation vs. membrane filtration) resulted in similar flavor profiles as compared to the rest of the techniques used to produce NAB (Table S6, excluding V2). As mentioned previously, these NABs also contained low amounts of fermentable carbohydrates/RE and higher concentrations of A2, A5, A6, A7, A8 A9, SA12, GLY, EST1, EST2, EST3, and 3-MBT (corresponding to ethyl acetate, isoamyl acetate, 2-methyl-1-butanol, 3-methyl-1-butanol, phenyl acetate, phenyl ethanol, ethyl nicotinate, glycerol, ethyl butyrate, ethyl hexanoate, ethyl octanoate, and 3-methyl-2-butene-1-thiol). These results once more highlight that NABs produced either with only biological methods or with only physical dealcoholization methods yield NABs that clearly vary in chemistry and sensory profiles.

It should be noted that the first two components explain the starkest differences in the data set even though they only explain $41.7 \%$ of the variance in the data set. As additional components are considered, these components just start to highlight the unique features of individual beers. For example, factor 3 explains an additional $12.7 \%$ of the variance within the data set (data not shown). However, this factor is only highlighting the differences in the concentrations of 2-methylpropanal, 2-methylbutanal, 3-methylbutanal, pentanal, methional, and phenylacetaldehyde between the membrane treatment and the vacuum treatments. As mentioned, these volatiles were the highest in the membrane treatment, whereas the vacuum treatment generally had the lowest concentrations of these analytes, 
except for ethyl nicotinate which on average was the highest in the vacuumed distilled NABs. However, as outlined previously these differences likely have a small impact on sensory because the sensory profiles of the membrane and vacuum distilled treatments were statistically similar (Table S6). Further, a higher percentage of the variation between the samples in the first two components can be explained if one reduces the input variables and processes the data only considering the differences in sensory (i.e., 65.5\%) or only the differences in chemistry (i.e., 44.7\%) using principle component analysis (data not shown). Given all the data that is reported in the manuscript and/or in the supplemental information, this can be explored further by an interested reader.

As outlined previously, numerous studies [1,14,15,17,38] have identified worty character as a key quality attribute in NAB. It is generally perceived to be a negative attribute associated with the presence of high concentrations of Strecker aldehydes. In this study, none of the volatiles measured were significantly positively correlated with worty character (Table 2). One possible explanation for this result could be that the perception of worty character might not be due to one specific volatile and that the presence/absence of other compositional factors might contribute more to the perception of worty quality. For example, there were several volatiles, most of them fermentation-related, that were negatively correlated to worty character (i.e., ethyl nicotinate, decanal, ethyl hexanoate, ethyl octanoate, ethyl acetate, 2-methyl-1-butanol, 3-methyl-1-butanol, and phenyl ethanol, Table 2). This suggests that along with preventing the production of Strecker aldehydes, the presence of these volatiles in NAB, which may result in higher concentrations due to flavor extract/hop additions, special yeast fermentations, etc. are crucial considerations to modifying and masking the perception of worty quality in NAB. This agrees with Gernat, Brouwer, Faber-Zirkzee, and Ottens [21] who found that the addition of fruity flavors and bitterness can mask worty character in NAB.

However, the observation that high concentrations of individual Strecker aldehydes were not directly correlated with high worty character is particularly interesting. For example, the physically dealcoholized membrane treated NAB (M1) had the highest concentrations of Strecker aldehydes but this NAB was also perceived to be one of the lowest in worty character amongst the NABs (Table S6). In comparison, the restricted fermentation treatment (RF3) contained moderate levels of Strecker aldehydes but was perceived to be one of the highest in worty character. One reason for this could be that as mentioned by Gernat, Brouwer, Faber-Zirkzee, and Ottens [21], aldehydes can also be associated with other characteristics such as aging/staling. However, although some panelists indicated these characteristics were present in the physically dealcoholized NABs, these attributes were not specifically evaluated in this study.

Another reason for this observation may be that in this study a number of different production techniques were evaluated, whereas past manuscripts $[17,21]$ trying to identify the drivers of worty character often only focused on evaluating NAB/treatments made from only biological techniques, which as seen in this study and others $[13,18]$ generally have significantly higher residual extracts. Interestingly, the fermentable sugars, most importantly Sug2 (i.e., maltose), were significantly positively correlated with worty character (Table 3). Notably, the nonvolatile profiles (i.e., residual extract, fermentable carbohydrates, etc.) of the samples perceived as most and least worty were extremely different from an analytical perspective. RF3 contained one of the highest maltose concentrations $(\sim 32 \mathrm{~g} / \mathrm{L})$ and one of the highest $\mathrm{pH}$ values, whereas $\mathrm{M} 1$ contained the lowest amount of maltose $(\sim 0.4 \mathrm{~g} / \mathrm{L})$ and the lowest $\mathrm{pH}(4.0)$. Therefore, it is hypothesized that the RE/carbohydrate profile and $\mathrm{pH}$ might also play a critical role in driving the worty quality of NAB and should be investigated in future studies.

Taken together, these results highlight that procedures (i.e., dry-hopping, the addition of aroma extracts, etc.) that add volatiles with fruity qualities, as well as the nonvolatile profile of NABs, have a significant impact on the perceived worty character in these products. Ultimately, if a brewer feels that worty character is an undesired trait and is 
to be avoided, these factors should also be considered along with previously reported strategies [38-40] to reduce the perception of worty character.

\subsection{Assessing the Importance of Pre- and Post-Processing Decisions on Pilsner-Style NAB Flavor}

In agreement with Ramsey, Yang, Fisk, and Ford [18], pre-processing steps (ex. V2 wort construction) and post-processing steps (ex. C9 and MI2; dry-hopping) also had a major influence on the resulting NAB flavor profile (Figure 2A).

As stated previously, ABV concentration is a critical consideration in NAB production from a legal perspective. In this study, as ABV increased the NABs became more harmonious (i.e., as one moves from the bottom of the plot to the top right in Figure 2). ABV was also significantly correlated with overall harmony (Table 3). One can also see that the combined treatments generally performed better from an overall flavor perspective than the treatments made only utilizing one technology (i.e., biological or physical dealcoholization) (Figure 2). In practice, commercial brewers consider the blending of several liquid streams as a reasonable way to balance beer quality and achieve optimal product consistency. As reported by the brewers of the NABs in this study, many of the C NABs were produced by blending an RF, V, or M NAB with fully-fermented alcoholic beer. In comparison, for the production of " 0.0 " $\mathrm{NAB}$, minor wort and/or RF beer volumes are added to vacuum dealcoholized beer. Based on our discussions with multiple commercial brewers, for NAB production, the addition of up to $10 \%$ (by volume) of fully-fermented beer with $5.0 \% \mathrm{ABV}$ has been suggested to yield more desired flavor profiles, whereas the addition of wort or RF beer to vacuum dealcoholized beer for " 0.0 " NAB can be helpful to enhance mouthfeel, palate fullness, and foam properties.

Although increasing ABV is not an option for products marketed as $0.0 \% \mathrm{ABV}$, blending in full-strength beer had a drastic impact on the resulting overall harmony, taste, and aroma qualities. For example, both $\mathrm{C} 2$ (i.e., a $0.0 \% \mathrm{NAB}$ ) and $\mathrm{C} 6$ were made by the same brewery but $\mathrm{C} 6$ was perceived to be more harmonious (Figure 2 and Table S6). These NABs represent a physically dealcoholized stream blended with either a NAB coming from a restricted fermentation (i.e., C2) or with a full-strength alcoholic beer (i.e., C6). Although $0.0 \% \mathrm{NABs}$ are marketed/produced for specific reasons, such as religious, health, etc., the addition of full-strength beer up to the legally permissible limit (i.e., $0.5 \%$ in Germany) resulted in NABs which had more harmonious flavor profiles. This observation agrees with previous studies that showed NABs with higher ABV were more beer-like [16] and more preferred by consumers [15].

Interestingly, two NABs produced through combined treatments were relatively low in $\mathrm{ABV}$ (i.e., $\mathrm{C} 7$ and $\mathrm{C} 3$ containing $0.08 \%$ and $0.16 \% \mathrm{ABV}$, respectively). It remains unclear why the brewers of these NABs did not take advantage of the legally justifiable ABV margin (i.e., $0.5 \%$ in Germany). The flavor perception of these NABs might be further improved if they were simply blended with a higher percentage of full-strength beer. However, when developing products that require blending different streams; issues such as cellar capacity, achieving thorough mixing, colloidal stability, etc. are also unique challenges that brewers need to consider/overcome from a practical standpoint. Further, the impact of the chemical profile for the full-strength alcoholic beer to be used for blending (i.e., BU, concentrations of hop/fermentation volatiles, $\mathrm{SO}_{2}$, etc.) on $\mathrm{NAB}$ flavor should be explored further in future studies.

The NABs with the most hop-forward chemical and flavor profiles, such as MI2 (i.e., the IPA) as well as C9, were also scaled highest in quality of taste, quality of aroma, and overall harmony (i.e., top right-hand quadrant Figure 2). Hop aroma was also highly correlated with overall harmony and bitterness quality (Table 3). Previous research has shown that consumers prefer NABs with hop-forward flavor profiles to varying levels $[13,18]$. However, NABs having low bitterness to moderate bitterness as well as high citrusy/fruity aromas imparted by hop terpenes/esters were previously shown to be largely preferred by American consumers [15]. As shown by several studies [14,19,34], this is because dry- 
hopping serves as a practical way to mask and/or compensate for the negative/lack of aroma attributes commonly associated with NAB.

In addition, as mentioned previously, the vacuum distilled V2 had a chemical and flavor profile similar to NABs that were made with restricted fermentation and is extremely different from the other physically dealcoholized NABs (i.e., it sits in the bottom right-hand quadrant of Figure 2). Again, one possible route to obtaining a NAB with these characteristics is the usage of a special mashing regime that limits the formation of fermentable sugars and this highlights that initial wort construction (i.e., mash profile, malt/adjunct variety/percentage, etc.) is extremely important for the flavor of NAB resulting from physical dealcoholization methods.

Lafontaine, Senn, Knoke, Schubert, Dennenlöhr, Maxminer, Cantu, Rettberg, and Heymann [16] also outlined previously that the type of beer style a brewer is trying to develop/recreate as an NAB will dictate the level of IBU and RE. For the pilsner beer style NABs in this study, there was a clear trend between bitterness intensity and IBU (i.e., mostly iso- $\alpha$-acids [41]) as well as between sweetness and RE (Table 3). As mentioned, the IBU ranged from 11 to 38 , while the RE ranged from 3.7 to 8.9 (g/100 g). Finding the right balance between RE and IBU is an important consideration because these factors have been shown to have a direct influence on the preferences consumers have towards NAB [15].

\section{Conclusions}

Overall, it is clear from the results that the commercial pilsner type NAB produced from single liquid streams or production technologies (i.e., biological or physical dealcoholization) tended to achieve lower scores for taste, aroma, and overall harmony compared to products from hybrid/combined methods. NABs produced via physical dealcoholization tended to have the lowest aromatic profiles and were sourer, whereas the NABs produced with restricted fermentation were generally the sweetest and most worty. While this is evidence that the initial production method used to produce NAB has a critical influence on the resulting flavor profile, it does not mean that one technique should be preferred over the other. For example, physical dealcoholization techniques could be used to generate a base that would be more neutral in flavor which could serve as a blank canvas and be blended/adjusted with other streams to create a NAB with a more multifaceted taste profile.

Additionally, pre- and post-processing steps were also determined to play significant roles in defining NAB flavor. For example, blending two liquid streams (particularly fullstrength alcoholic beer) up to the legally allowable limit seems to be a practical approach to achieve NABs with multifaceted and more harmonious flavor profiles. Additionally, NABs containing detectable levels of hop aroma compounds were perceived to be the most harmonious by the sensory panel. Hops contain multiple volatiles (i.e., terpenes, esters, thiols, etc.) $[42,43]$ that are directly extracted during dry-hopping and these volatiles can be far more flavor active than the volatiles which may be produced during the limited fermentation in NAB production via yeast metabolism (i.e., acetate and ethyl esters). Even low levels of terpenes, terpenoids, and hop-derived esters were found to increase NAB flavor by compensating low levels of fermentation-derived alcohols and esters. This again shows that late kettle hopping and/or dry-hopping can serve as potential practical applications to improve NAB flavor.

Given that fruity flavor profiles are not necessarily characteristic of the aroma profiles of pilsner style beers, brewers must consider how much hop aroma as well as which aroma qualities are acceptable to produce a NAB with their desired attributes. Nevertheless, brewers have a lot of flexibility in the flavors they can impart given the range of aromas that can be generated in beer from using the unique characteristics of single-hop varieties, blends of different hop varieties, and/or advanced hop products [34,41,42]. Additionally, because this study was specifically focused on evaluating commercial pilsner-style NAB available in the German market, as compared to the addition of natural/artificial flavoring which may be allowed in other countries but not Germany, dry-hopping has the potential 
to practically improve the flavor quality of NAB while still being in the bounds of the Reinheitsgebot (i.e., the beer purity law).

Interestingly, the data presented herein suggest that additional compositional factors, other than just the presence of aldehydes, might also be responsible for the perception of worty character in NAB. For example, maltose concentrations were significantly positively correlated with the worty character, whereas $\mathrm{pH}$, hop, and fermentation-derived flavors were shown to mask worty perception. Ultimately, it is up to the brewer to decide what techniques are the most suitable for them to produce NAB based on their existing infrastructure as well as which will lead to them to create products that will best meet their desired flavor profiles.

Supplementary Materials: The following are available online at https://www.mdpi.com/article/ 10.3390/beverages8010004/s1, Table S1: Additional nonvolatile analysis results, Table S2: Concentrations of acetaldehyde, higher alcohols, and esters $(\mathrm{mg} / \mathrm{L})$ as well as the concentration of 3-MBT $(\mathrm{ng} / \mathrm{L})$, Table S3: Concentration of staling aldehydes and ethyl nicotinate $(\mu \mathrm{g} / \mathrm{L})$, Table S4: Concentrations of hop derived aroma compounds, ethyl esters and DMS ( $\mu \mathrm{g} / \mathrm{L})$, Figure S1. Ballot used for modified descriptive analysis., Table S5. Mixed model analysis of variance on the sensory attributes, Table S6: Least square mean values sensory terms sorted by overall harmony.

Author Contributions: Conceptualization, N.R. and S.L.; methodology, N.R.; validation, N.R., S.L. and S.T.; formal analysis, N.R. and S.L.; investigation, N.R., S.L., C.S., J.D., L.K., P.D.F., J.F. and S.T.; resources, N.R.; data curation, N.R., S.L., C.S., J.D., L.K., P.D.F., J.F. and S.T.; writing-original draft preparation, N.R. and S.L.; writing-review and editing, N.R. and S.L.; visualization, N.R. and S.L.; supervision, N.R.; project administration, N.R. and S.T.; funding acquisition, N.R. All authors have read and agreed to the published version of the manuscript.

Funding: The instrument used for HS-SPME-GC-MS/MS analysis of hop aroma compounds, staling aldehydes, and 3-MBT was funded by the German Federal Ministry for Economic Affairs and Energy under grant number IZ140016.

Informed Consent Statement: Informed consent was obtained from all subjects involved in the study.

Acknowledgments: The authors acknowledge Jörg Maxminer (formerly VLB Berlin) for supporting this work and all members of the VLB beer taster panel that have been contributing to the data collection. The Alexander von Humboldt Foundation is recognized for funding Scott Lafontaine's postdoctoral research fellowship hosted by the Versuchs-und Lehranstalt für Brauerei in Berlin (VLB) e.V.

Conflicts of Interest: The authors declare no conflict of interest.

\section{References}

1. Bellut, K.; Arendt, E.K. Chance and Challenge: Non-Saccharomyces Yeasts in Nonalcoholic and Low Alcohol Beer Brewing-A Review. J. Am. Soc. Brew. Chem. 2019, 77, 77-91. [CrossRef]

2. Ahrens, S. Statistiken zum Thema Bier. 2020. Available online: https://de.statista.com/themen/87/bier/ (accessed on 28 April 2021).

3. Gribbins, K. No and Low Alcohol Beer Grew 30+ Percent Last Year, Now Enjoy Some Big Haps in the NA Beer Sector; CBB Media LLC: Medina, Saudi Arabia, 2021.

4. Brányik, T.; Silva, D.P.; Baszczyňski, M.; Lehnert, R.; Almeida e Silva, J.B. A review of methods of low alcohol and alcohol-free beer production. J. Food Eng. 2012, 108, 493-506. [CrossRef]

5. Güzel, N.; Güzel, M.; Savaş Bahçeci, K. Chapter 6-Nonalcoholic Beer. In Trends in Non-Alcoholic Beverages; Galanakis, C.M., Ed.; Academic Press: Cambridge, MA, USA, 2020; pp. 167-200. [CrossRef]

6. Howe, S. Coutdown to Zero. The Search for the Perfect Alcohol-Free Beer. Brewer \& Distiller International, IBD Coffee Break. 2020. Available online: https:/ / online.flippingbook.com/view/575817/2/ (accessed on 1 May 2021).

7. Sohrabvandi, S.; Mousavi, S.M.; Razavi, S.H.; Mortazavian, A.M.; Rezaei, K. Alcohol-free Beer: Methods of Production, Sensorial Defects, and Healthful Effects. Food Rev. Int. 2010, 26, 335-352. [CrossRef]

8. Zürcher, A. Alkoholfreies Bier. In Ausgewählte Kapitelder Brauereitechnologie; Back, W., Ed.; Fachverlag Hans Carl: Nuremberg, Germany, 2008.

9. Binding-Brauerei AG Company. Verfahren zur Herstellung von Alkoholfreiem Bzw. Alkoholarmem Bier. German Patent DT 26 29666,8 June 1977. 
10. Montanari, L.; Marconi, O.; Mayer, H.; Fantozzi, P. 6-Production of Alcohol-Free Beer. In Beer in Health and Disease Prevention; Preedy, V.R., Ed.; Academic Press: San Diego, CA, USA, 2009; pp. 61-75. [CrossRef]

11. Mangindaan, D.; Khoiruddin, K.; Wenten, I.G. Beverage dealcoholization processes: Past, present, and future. Trends Food Sci. Technol. 2018, 71, 36-45. [CrossRef]

12. Müller, M.; Bellut, K.; Tippmann, J.; Becker, T. Physical Methods for Dealcoholization of Beverage Matrices and their Impact on Quality Attributes. ChemBioEng Rev. 2017, 4, 310-326. [CrossRef]

13. Schmelzle, A.; Lindemann, B.; Methner, F.-J. Sensory descriptive analysis and consumer acceptance of non-alcoholic beer. Brew.-Mon. Brauwiss. 2013, 66, 144-153.

14. Brendel, S.; Hofmann, T.; Granvogl, M. Dry-Hopping to Modify the Aroma of Alcohol-Free Beer on a Molecular Level-Loss and Transfer of Odor-Active Compounds. J. Agric. Food Chem. 2020, 68, 8602-8612. [CrossRef]

15. Lafontaine, S.; Senn, K.; Dennenlöhr, J.; Schubert, C.; Knoke, L.; Maxminer, J.; Cantu, A.; Rettberg, N.; Heymann, H. Characterizing Volatile and Nonvolatile Factors Influencing Flavor and American Consumer Preference toward Nonal-coholic Beer. ACS Omega 2020, 5, 23308-23321. [CrossRef]

16. Lafontaine, S.; Senn, K.; Knoke, L.; Schubert, C.; Dennenlöhr, J.; Maxminer, J.; Cantu, A.; Rettberg, N.; Heymann, H. Evaluating the Chemical Components and Flavor Characteristics Responsible for Triggering the Perception of "Beer Flavor" in Non-Alcoholic Beer. Foods 2020, 9, 1914. [CrossRef]

17. Piornos, J.A.; Balagiannis, D.P.; Methven, L.; Koussissi, E.; Brouwer, E.; Parker, J.K. Elucidating the Odor-Active Aroma Compounds in Alcohol-Free Beer and Their Contribution to the Worty Flavor. J. Agric. Food Chem. 2020, 68, 10088-10096. [CrossRef]

18. Ramsey, I.; Yang, Q.; Fisk, I.; Ford, R. Understanding the sensory and physicochemical differences between commercially produced non-alcoholic lagers, and their influence on consumer liking. Food Chem. X 2021, 9, 100114. [CrossRef]

19. Forster, A.; Gahr, A. Hopping of low alcohol beers. BrewingScience 2012, 65, 72-82.

20. Institut für Rechtsinformatik. Vorläufiges Biergesetz. In Bundesgesetzblatt; Teil I Seite 1400; Institut für Rechtsinformatik, Universität des Saarlandes: Saarbrücken, Germany, 1993. Available online: http://archiv.jura.uni-saarland.de/BGBl/TEIL1/199 3/19931400.1 (accessed on 29 April 2021).

21. Gernat, D.C.; Brouwer, E.R.; Faber-Zirkzee, R.C.; Ottens, M. Flavour-improved alcohol-free beer-Quality traits, ageing and sensory perception. Food Bioprod. Process. 2020, 123, 450-458. [CrossRef]

22. Committee, E.A. Analytica-EBC; Fachverlag Hans Carl: Nurnberg, Germany, 2008.

23. Jacob, F.; Analysenkommission, M.B. Wort, Beer, Beer-Based Beverages: Collection of Brewing Analysis Methods of the Mitteleuropäische Brautechnische Analysenkommission; Selbstverl. der MEBAK: Nürnberg, Germany, 2013.

24. Dennenlöhr, J.; Thörner, S.; Manowski, A.; Rettberg, N. Analysis of Selected Hop Aroma Compounds in Commercial Lager and Craft Beers Using HS-SPME-GC-MS/MS. J. Am. Soc. Brew. Chem. 2020, 78, 16-31. [CrossRef]

25. Dennenlöhr, J.; Thörner, S.; Maxminer, J.; Rettberg, N. Analysis of Selected Staling Aldehydes in Wort and Beer by GC-EI-MS/MS Using HS-SPME with On-Fiber Derivatization. J. Am. Soc. Brew. Chem. 2020, 78, 284-298. [CrossRef]

26. Dennenlöhr, J.; Thörner, S.; Rettberg, N. Analysis of Hop-Derived Thiols in Beer Using On-Fiber Derivatization in Combination with HS-SPME and GC-MS/MS. J. Agric. Food Chem. 2020, 68, 15036-15047. [CrossRef]

27. Heymann, H.; King, E.S.; Hopfer, H. Classical descriptive analysis. In Novel Techniques in Sensory Characterization and Consumer Profiling; CRC Press: Boca Raton, FL, USA, 2014; pp. 9-40.

28. Bellut, K.; Michel, M.; Zarnkow, M.; Hutzler, M.; Jacob, F.; Lynch, K.M.; Arendt, E.K. On the suitability of alternative cereals, pseudocereals and pulses in the production of alcohol-reduced beers by non-conventional yeasts. Eur. Food Res. Technol. 2019, 245, 2549-2564. [CrossRef]

29. Verstrepen, K.J.; Derdelinckx, G.; Dufour, J.-P.; Winderickx, J.; Thevelein, J.M.; Pretorius, I.S.; Delvaux, F.R. Flavor-active esters: Adding fruitiness to beer. J. Biosci. Bioeng. 2003, 96, 110-118. [CrossRef]

30. Schieberle, P. Primary odorants of pale lager beer. Z. Lebensm.-Unters. Forsch. 1991, 193, 558-565. [CrossRef]

31. Vanderhaegen, B. Low Alcohol or Alcohol Free Fermented Malt Based Beverage and Method for Producing It. E.P. Patent EP2804942A1, 31 October 2018.

32. Xu, Y.; Wang, D.; Li, G.; Hao, J.; Jiang, W.; Liu, Z.; Qin, Q. Flavor Contribution of Esters in Lager Beers and an Analysis of Their Flavor Thresholds. J. Am. Soc. Brew. Chem. 2017, 75, 201-206. [CrossRef]

33. Vesely, P.; Lusk, L.; Basarova, G.; Seabrooks, J.; Ryder, D. Analysis of Aldehydes in Beer Using Solid-Phase Microextraction with On-Fiber Derivatization and Gas Chromatography/Mass Spectrometry. J. Agric. Food Chem. 2003, 51, 6941-6944. [CrossRef]

34. Schönberger, C.; Korn, S.; Marriott, R. Evaluations of pure hop aromas in alcohol free beer. Brauwelt Int. 2005, 3, $181-184$.

35. Takoi, K.; Itoga, Y.; Koie, K.; Kosugi, T.; Shimase, M.; Katayama, Y.; Nakayama, Y.; Watari, J. The Contribution of Geraniol Metabolism to the Citrus Flavour of Beer: Synergy of Geraniol and $\beta$-Citronellol Under Coexistence with Excess Linalool. J. Inst. Brew. 2010, 116, 251-260. [CrossRef]

36. Huvaere, K.; Andersen, M.L.; Skibsted, L.H.; Heyerick, A.; De Keukeleire, D. Photooxidative Degradation of Beer Bittering Principles: A Key Step on the Route to Lightstruck Flavor Formation in Beer. J. Agric. Food Chem. 2005, 53, 1489-1494. [CrossRef]

37. Schönberger, C.; Kostelecky, T. 125th anniversary review: The role of hops in brewing. J. Inst. Brew. 2011, 117, 259-267. [CrossRef]

38. Gernat, D.C.; Brouwer, E.; Ottens, M. Aldehydes as Wort Off-Flavours in Alcohol-Free Beers-Origin and Control. Food Bioprocess Technol. 2019, 13, 195-216. [CrossRef] 
39. Perpète, P.; Collin, S. Influence of beer ethanol content on the wort flavour perception. Food Chem. 2000, 71, 379-385. [CrossRef]

40. Perpète, P.; Collin, S. How to improve the enzymatic worty flavour reduction in a cold contact fermentation. Food Chem. 2000, 70, 457-462. [CrossRef]

41. Hahn, C.D.; Lafontaine, S.R.; Pereira, C.B.; Shellhammer, T.H. Evaluation of Nonvolatile Chemistry Affecting Sensory Bitterness Intensity of Highly Hopped Beers. J. Agric. Food Chem. 2018, 66, 3505-3513. [CrossRef]

42. Lafontaine, S.; Shellhammer, T. Investigating the Factors Impacting Aroma, Flavor, and Stability in Dry-Hopped Beers. MBAA TQ 2019, 56, 13-23. [CrossRef]

43. Rettberg, N.; Biendl, M.; Garbe, L.-A. Hop Aroma and Hoppy Beer Flavor: Chemical Backgrounds and Analytical Tools-A Review. J. Am. Soc. Brew. Chem. 2018, 76, 1-20. [CrossRef] 